\title{
REVIEW
}

\section{Rho GTPase signalling networks in cancer cell transendothelial migration}

\author{
Wessel S Rodenburg1 and Jaap D van Buul(D1,2 \\ ${ }^{1}$ Molecular Cell Biology Lab at Department of Molecular Hematology, Sanquin Research and Landsteiner Laboratory, Amsterdam, the Netherlands \\ 2Leeuwenhoek Centre for Advanced Microscopy, Section Molecular Cytology at Swammerdam Institute for Life Sciences at University of Amsterdam, \\ Amsterdam, the Netherlands
}

Correspondence should be addressed to J D van Buul: j.vanbuul@sanquin.nl

\begin{abstract}
Rho GTPases are small signalling G-proteins that are central regulators of cytoskeleton dynamics, and thereby regulate many cellular processes, including the shape, adhesion and migration of cells. As such, Rho GTPases are also essential for the invasive behaviour of cancer cells, and thus involved in several steps of the metastatic cascade, including the extravasation of cancer cells. Extravasation, the process by which cancer cells leave the circulation by transmigrating through the endothelium that lines capillary walls, is an essential step for metastasis towards distant organs. During extravasation, Rho GTPase signalling networks not only regulate the transmigration of cancer cells but also regulate the interactions between cancer and endothelial cells and are involved in the disruption of the endothelial barrier function, ultimately allowing cancer cells to extravasate into the underlying tissue and potentially form metastases. Thus, targeting Rho GTPase signalling networks in cancer may be an effective approach to inhibit extravasation and metastasis. In this review, the complex process of cancer cell extravasation will be discussed in detail. Additionally, the roles and regulation of Rho GTPase signalling networks during cancer cell extravasation will be discussed, both from a cancer cell and endothelial cell point of view.
\end{abstract}

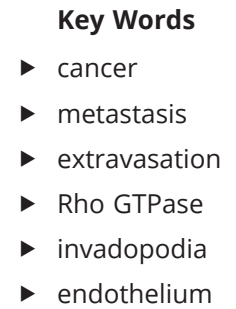

Key Words

- extravasation

- Rho GTPase

- endothelium

\section{Introduction}

\section{The multistep process of metastasis formation}

Metastasis is the process by which tumour cells disseminate from the primary tumour and spread towards distant sites to form secondary tumours. Of all cancer-related deaths, the great majority is caused by metastases (1). Strikingly, despite all advances that have been made in cancer treatment, the 5-year survival rate of metastatic disease has barely increased in the last two decades and remains under $30 \%$ for most cancer types (2). Yet, the complex process of metastasis remains incompletely understood. To target this process and improve patient outcome, it is essential to better understand each step and the molecular players involved.
Formation of metastases involves multiple steps (Fig. 1A). First, tumour cells disseminate from the primary tumour by activating an epithelial-mesenchymal transition (EMT) programme (3), followed by local invasion of the surrounding tissue and extracellular matrix (ECM). Next, cancer cells can penetrate a nearby blood vessel wall (intravasation) and are transported through the circulation. While in the circulation, cancer cells are referred to as circulating tumour cells (CTCs). At a distant site, CTCs can get trapped, which often occurs in small capillaries, and subsequently transmigrate through the capillary wall, a process called extravasation $(4,5)$. Cancer cells that have extravasated are frequently unable to survive, but may, in

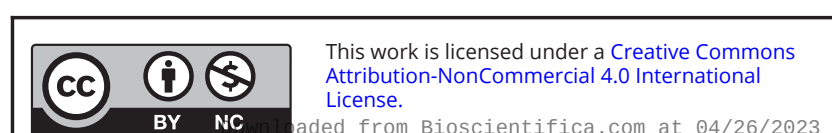
aled from Bioscientifica.com at 04/26/2023 01:51:28PM 
A

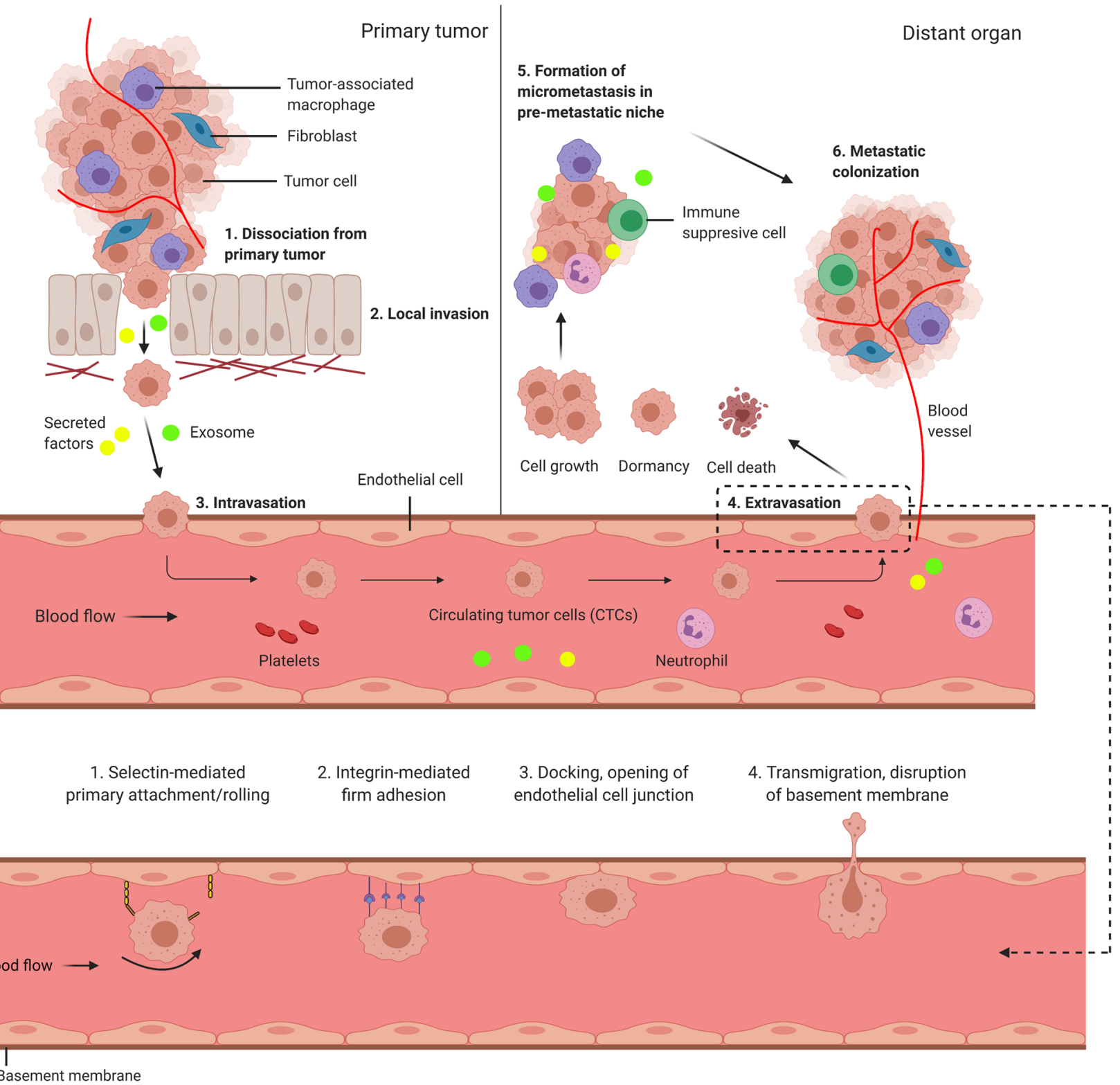

\section{Figure 1}

Schematic overview of metastasis formation to distant organs. (A) Metastasis formation is a complex process consisting of multiple steps: dissociation from the primary tumour (1), local invasion (2), intravasation (3), extravasation (4), formation of a micrometastasis (5) and metastatic colonization (6). Given its complexity, only a small fraction of disseminated tumour cells may ultimately form a metastatic lesion. (B) Extravasation involves many interactions between endothelial cells (ECS) and invasive circulating tumour cells (CTCs). These interactions are mediated by cell-adhesion molecules such as selectins and integrins expressed on their cell surfaces (step 1-3 rolling, adhesion and docking), which may ultimately result in the transmigration of CTCs into the underlying tissue (step 4 transmigration).

rare cases, form a micro-metastasis by activating a reversed EMT programme, known as a mesenchymal-epithelial transition (MET) programme, which can even occur after years of dormancy (2). The formation of a micro-metastasis can be followed by metastatic colonization, ultimately resulting in a secondary tumour in a distant organ (6).

Extravasation, also known as transendothelial migration (TEM), is an essential step for metastasis towards Published by Bioscientifica Ltd distant organs. Similar to leukocyte extravasation, CTCs form many selectin- and integrin-mediated interactions with endothelial cells (ECs) that line capillary walls $(5,7)$ (Fig. 1B). Upon these interactions, intracellular signalling is induced in ECs, which contributes to local disruption of the endothelial barrier. Additionally, CTCs secrete factors that increase vascular permeability or induce apoptosis or necroptosis in ECs $(5,7,8,9)$. CTCs can 
subsequently transmigrate through the barrier by forming membrane protrusions such as invadopodia (10). Despite its importance in metastatic disease, the complex process of cancer cell extravasation and the molecular mechanisms involved remain incompletely understood. A better understanding of these mechanisms may result in novel targeting strategies to reduce extravasation and metastasis.

\section{The family of Rho GTPases}

During the process of extravasation, CTCs need to continuously induce changes in their cell shape to adhere and transmigrate through the endothelium. Similarly, ECs form protrusions and alter their cell-cell adhesion to create an opening in the barrier. These processes require remodelling of the actin cytoskeleton, which is centrally regulated by Rho GTPase signalling networks (5). Rho GTPases form a family of 20 small signalling G-proteins and are a part of the Ras GTPase superfamily that is known for its central role in cancer (11). Rho GTPases are active at cellular membranes, where they function as signal transducers to activate downstream effector pathways (11). In this way, Rho GTPases not only regulate cancer cell extravasation but are involved in many other aspects of cancer development, including cell transformation and growth (12), cancer cell motility and invasion (13) and angiogenesis (12, 14). In addition, Rho GTPases are involved in the regulation of the cell cycle, cellular adhesion and cellular polarity (15). Because of their wide variety of functions, Rho GTPases are tightly regulated.

In fact, 'typical' Rho GTPases are regulated in a cycle, in which they are either in an active GTP-bound conformation or in an inactive GDP-bound conformation (15). Three types of molecules regulate the activity of 'typical' Rho GTPases. Guanine nucleotide exchange factors (GEFs) activate Rho GTPases by catalysing the exchange of GDP for GTP. GTPase-activating proteins (GAPs) inactivate Rho GTPases by a GTP-hydrolysis reaction. Guanine nucleotide dissociation inhibitors (GDIs) solubilize Rho GTPases in the cytosol, thereby preventing it to be localized at membranes (16). Rho GTPases, their effectors and their regulating GEFs, GAPs and GDIs are dysregulated in many types of cancer (17) and are considered as promising therapeutic targets in metastatic disease (18).

In this review, the mechanisms by which cancer cells extravasate through the endothelial barrier will be discussed in detail. Additionally, the roles and regulation of Rho GTPase signalling networks in cancer cell extravasation will be discussed, both from a cancer cell and endothelial cell point of view.

\section{The multistep process of cancer cell extravasation}

Extravasation (or TEM) not only occurs during metastasis but is also the process by which leukocytes transmigrate through the endothelium towards sites of infection. The process of cancer cell extravasation is to a great extent similar to that of leukocytes. In fact, CTCs exploit the mechanisms by which leukocytes adhere to and transmigrate through ECs $(7,19)$. Therefore, in this part, the current knowledge on cancer cell extravasation will be discussed and compared to leukocyte extravasation.

Extravasation of both leukocytes and CTCs can be divided into four steps: selectin-mediated primary attachment/rolling, integrin-mediated firm adhesion, docking/formation of protrusions and transmigration (20, 21) (Fig. 1B).

Step 1: The first step, primary attachment/rolling, involves many low-affinity interactions, allowing leukocytes or CTCs to 'roll' over the endothelium $(7,21)$ (Fig. 2A). It functions as a primary attachment and slow down leukocytes or CTCs in the circulation. This process is mainly mediated by E-selectin and P-selectin expressed on ECs $(19,21)$. Leukocytes can bind to these selectins via the expression of L-selectin and PSGL-1 on their surfaces $(21,22)$. PSGL-1 was also shown to mediate extravasation of multiple myeloma cells by interacting with P-selectin expressing ECs (23). However, CTCs generally do not express these E- and P-selectin ligands and instead, express a wide variety of cell-adhesion molecules (CAMs) that have binding affinity for the selectins present on ECs. The CAMs expressed by CTCs to mediate this first step vary per type of cancer. Rolling of colon carcinoma cells is, for example, mediated via isoforms of CD44 that are ligands for $\mathrm{P}-$, L and E-selectin (24). In breast carcinoma cells, CD24 acts as a ligand for P-selectin (25), and in pancreatic cancer cells, MUC16 and PODXL are E- and L-selectin ligands to mediate rolling (26). In addition, $\mathrm{N}$-cadherin expressed on both ECs and CTCs can act as a mediator of rolling, for example during extravasation of breast carcinoma cells (27). As another mechanism, CTCs can use their CAMs to bind to P-selectin expressing platelets. These platelets subsequently adhere to ECs, thereby functioning as an intermediate to allow primary attachment of CTCs $(19,28)$ (Fig. 2A).

It should be noted that rolling over ECs is essential during leukocyte extravasation, but it does not always seem to occur in cancer cell extravasation. Although many in vitro studies show that selectin-mediated rolling of CTCs over ECs does occur $(25,26,27,29)$, in vivo evidence using microscopy techniques is lacking. For example,

This work is licensed under a Creative Commons Attribution-NonCommercial 4.0 International License. 

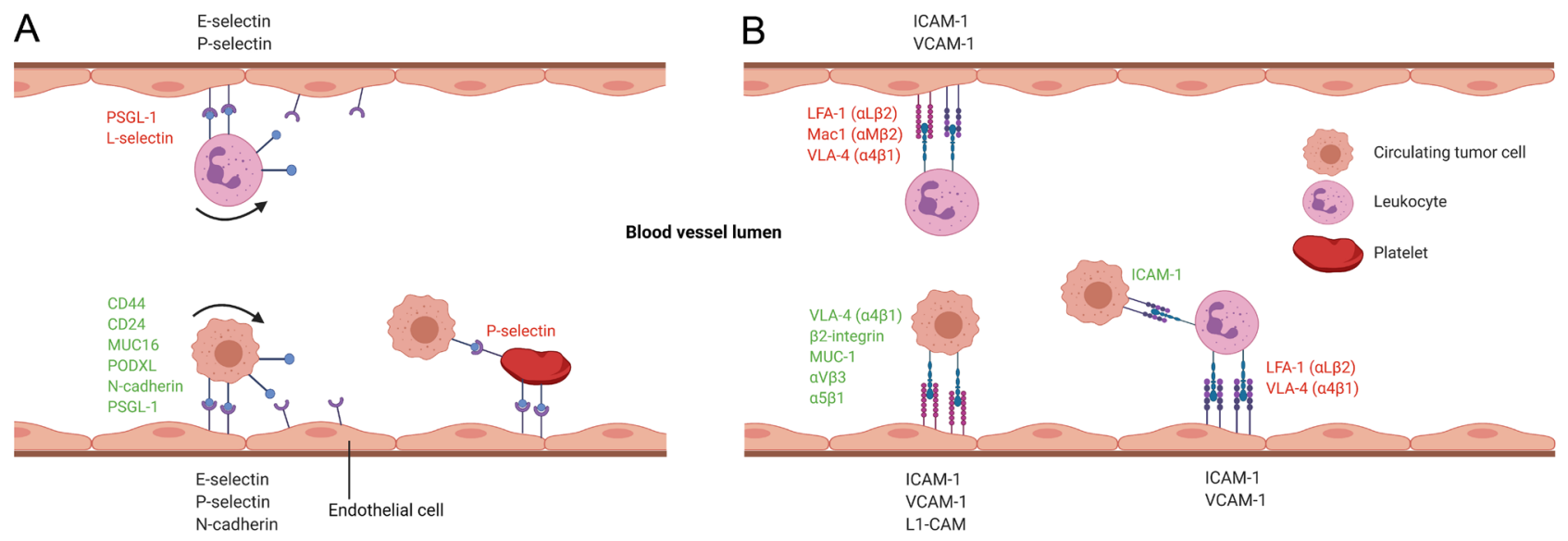

Figure 2

Adhesion of leukocytes (upper part) and circulating tumour cells (lower part) to ECs during extravasation. (A) Step 1: rolling/primary attachment. This step is mediated by selectins. Leukocytes express PSGL-1 and L-selectin to directly roll over E- and P-selectin expressing ECs. CTCS, on the other hand, generally do not express these molecules and instead express a wide variety of CAMs to bind to selectins on ECs, or use P-selectin expressing platelets as intermediates. (B) Step 2: firm adhesion. Leukocytes express $\beta 1$ or $\beta 2$ integrins (LFA-1, Mac1, VLA-4) to directly firmly adhere to ECs. Some CTCs do express VCAM-1, ICAM-1 and L1-CAM ligands to directly firmly adhere to ECs, but CTCS can also use circulating leukocytes as intermediates by expressing ICAM-1 themselves. CAMs expressed by CTCs are shown in green, CAMs expressed by circulating leukocytes/platelets are shown in red, and CAMs expressed by ECs are shown in black.

multiphoton imaging could show a reduction of CTC velocity in capillaries followed by a complete arrest, but rolling was not observed $(30,31)$. Possibly, as CTCs usually arrest and extravasate in small capillaries, size restriction of the capillary rather than rolling over ECs functions to slow down and capture CTCs (31), followed by firm adhesion (step 2). In line with this hypothesis, it was shown that blocking E-, P- and L-selectin using monoclonal antibodies did not significantly affect metastatic deposit formation of the prostate and breast cancer cells in vivo (32), indicating that selectin-mediated attachment is not essential for extravasation of these cancer cells. Taken together, the occurrence of primary attachment/rolling and the selectins and CAMs involved differs per type of cancer cell and per type of endothelium and does not always appear to be essential for arrest and extravasation.

Step 2: Next, both leukocytes and CTCs need to firmly adhere to ECs (Fig. 2B). Whereas the first step functions as a primary attachment to capture leukocytes or CTCs, the second step is essential to form a strong interaction (21). Firm adhesion during extravasation is mediated by integrins. Integrins are heterodimeric transmembrane receptors consisting of $\alpha$ - and $\beta$-subunit. Ligands of integrins not only mainly include extracellular matrix proteins but also a few cell-adhesion molecules such as ICAM-1 and VCAM-1 (19). As such, ECs express ICAM-1 and VCAM-1 on their surfaces under inflammatory conditions, to which leukocytes can bind using integrins (21). These integrins are mainly $\beta 1$ - and $\beta 2$-integrins, such as LFA-1
( $\alpha \mathrm{L} \beta 2$; an ICAM-1 ligand), Mac-1 ( $\alpha \mathrm{M} \beta 2$; an ICAM-1 ligand) and VLA-4 ( $\alpha 4 \beta 1$; a VCAM-1 ligand), allowing leukocytes to firmly attach to ECs $(19,21)$ (Fig. 2B).

Firm adhesion of CTCs to ECs is also mediated by integrins but is slightly different compared to leukocytes and can be performed in multiple ways (Fig. 2B). First, CTCs express few integrins themselves, depending on the type of cancer. Several types of cancer cells have been shown to express VLA-4 $(\alpha 4 \beta 1)$, a VCAM- 1 ligand $(19,33)$. For instance, ovarian cancer cells express VLA-4 ( $\alpha 4 \beta 1)$, and its interaction with VCAM-1 facilitates peritoneal metastasis formation (34). Additionally, VLA-4-VCAM-1 interactions have been shown to enhance the extravasation of melanoma cells through endothelial cell layers (35) and are important for metastasis of breast cancer cells towards the brain (36).

Apart from VLA-4-VCAM-1 interactions, it has been shown that a wide variety of cancer cell types expresses $\beta 2$-integrin and/or MUC1, both ICAM-1 ligands, allowing CTCs to adhere to ICAM- 1 expressing ECs $(37,38)$. For instance, the expression of LFA- 1 and ICAM- 1 was shown to enhance the extravasation of melanoma cells through endothelial monolayers (39). However, not all CTCs express these ICAM-1 ligands. Instead, CTCs can express ICAM-1 themselves to bind to circulating leukocytes, such as neutrophil granulocytes (27). These leukocytes subsequently adhere to ECs, as they do express the required ICAM-1 ligands $(19,27)$. Finally, several types of CTCs have been shown to adhere to ECs via the interaction of L1-CAM with $\alpha \mathrm{V} \beta 3$ and/or $\alpha 5 \beta 1$ integrins (19). Taken together,

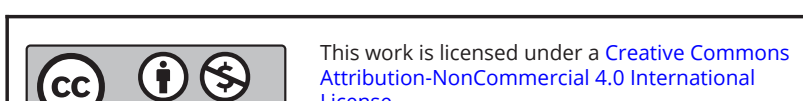
Attribution-NonCommercial 4.0 International License. 
CTCs either express integrins themselves or exploit circulating leukocytes to firmly adhere to ECs. This integrin-mediated firm adhesion subsequently induces the next step, docking and formation of protrusions.

Step 3: The third step of extravasation involves the formation of protrusions by ECs. The ICAM-1- and VCAM1-mediated firm adhesion (step 2) of leukocytes triggers ECs to redistribute ICAM-1 and VCAM-1 in so-called 'cup-like structures' that are supported by the actin cytoskeleton (21, 40). As such, ICAM-1 and VCAM-1-rich structures are formed around transmigrating leukocytes, providing a surface to which LFA-1/VLA-4-expressing leukocytes can adhere (also known as 'docking'). Several types of such structures have been identified, including docking structures (41), transmigratory cups (42) and endothelial domes (43). Although uncertainty remains about the function of these structures, they appear to be directly involved in initiating the final transmigration step $(21,42)$. Similar protrusions were also recognized in cancer cell transendothelial migration, but the evidence is limited and very little is known about it. Using confocal microscopy, it was shown that the endothelium forms transient protrusions upon adhesion of breast cancer cells (44). These protrusions could subsequently form into cup-like structures and even engulf the CTC. More recently, using transmission electron microscopy, it was shown that brain endothelium forms protrusions that extend towards transmigrating CTCs both in vitro and in vivo (45). In some cases, this could lead to incorporation of the CTC into the endothelium, thereby possibly facilitating transmigration. Taken together, the formation of EC protrusions appears to play an important role in both leukocyte and cancer cell extravasation and initiation of the final step: transmigration.

Step 4: Lastly, leukocytes or CTCs must cross the endothelial barrier, a process called diapedesis or transmigration. Both leukocytes and CTCs can cross the endothelial barrier either via the paracellular route (through EC junctions) or via the transcellular route (through an EC body) $(7,21)$. The 'decision' about which route is taken is dependent on characteristics of both the endothelium and the invading cell; however, the paracellular route appears to be the most common $(46,47)$. For example, invading melanoma cells utilize the paracellular route to transmigrate through the brain epithelium, whereas breast cancer cells are also able to use the transcellular route (45).

Paracellular transmigration: For paracellular transmigration to occur, the EC junctions must be disrupted. Firm adhesion of leukocytes to ECs (step 2), supported by EC protrusions (step 3), involves many ICAM-1/VCAM-1-mediated interactions. Upon these interactions, ICAM-1 and VCAM-1 induce intracellular EC signalling, which often results in the activation of kinases, followed by phosphorylation of molecules involved in the endothelial barrier function (48). For instance, ICAM-1 signalling can induce tyrosine phosphorylation of VE-cadherin at Tyr658 and Tyr731 via the activation of two tyrosine kinases, Src and Pyk2 (49). VE-cadherin is a major constituent of adherens junctions and connects ECs by binding to the actin cytoskeleton (48). Phosphorylation of VE-cadherin at certain serine or tyrosine residues located in its cytoplasmic domain results in reduced binding to the actin cytoskeleton and disruption of EC junctions (48). For example, phosphorylation of Tyr685 results in increased vascular permeability, and phosphorylation of Tyr658 and Tyr731 facilitate leukocyte diapedesis $(49,50)$. Similarly, adhesion of neutrophils and monocytes can induce phosphorylation of myosin light chain (MLC) by myosin light chain kinase (MLCK) on Thr18 and Ser19, a process mediated by RhoA-ROCK signalling (21, 51, 52). MLC phosphorylation on Thr18 and Ser19 results in actomyosin contraction, potentially followed by retraction of ECs and thereby the formation of a gap $(52,53)$. Intracellular signalling in ECs is also important in the paracellular transmigration of CTCs. Like leukocytes, the adhesion of CTCs to ECs can trigger signalling events resulting in local disruption of the endothelial barrier function. For instance, phosphorylation of VE-cadherin and MLC is also involved in EC junction opening in cancer cell paracellular transmigration $(5,8,54,55,56)$. In addition, it has been shown that transmigrating CTCs can downregulate cell adhesion molecules. For example, the highly invasive MDA-MB-231 breast cancer cells downregulate VE-cadherin and PECAM-1, which decrease cell-cell adhesion and result in a local breakdown of the endothelial barrier (57).

Finally, CTCs secrete a variety of factors that induce the opening of EC junctions, such as pro-apoptotic factors and chemokines (5). Importantly, in both leukocyte and cancer cell extravasation, the disruption of the endothelial barrier via intracellular signalling in ECs is centrally regulated by Rho GTPase signalling networks, which will be discussed in greater detail later.

Transcellular transmigration: The process of transcellular transmigration remains poorly understood. In leukocyte extravasation, it was shown that leukocytes form 'invasive podosomes', both in vitro and in vivo, that extend through transcellular pores in ECs, which was one of the first in vivo evidence of transcellular transmigration (58). Additionally, it was shown that approximately one-third of lymphocytes transmigrate via the transcellular route on human dermal and lung microvascular endothelial

This work is licensed under a Creative Commons Attribution-NonCommercial 4.0 International License. 
monolayers and approximately $10 \%$ on human umbilical vein endothelial monolayers (58). Another study showed that transcellular transmigration of lymphocytes occurred in the range of $\sim 30-70 \%$ depending on the type of endothelium (46). The 'decision' about the preferred route could be based on the 'route of least resistance' idea, as high barrier function (e.g. brain epithelium) is associated with predominant transcellular transmigration (46). Another hypothesis is that the amount of ICAM-1 expressed on the surface of inflamed ECs may determine which route is taken (47). This is supported by the finding that interfering with ICAM-1 expression preferentially inhibits transcellular transmigration (59). Nonetheless, it is clear that transcellular transmigration plays an important role in leukocyte extravasation. This raised the question of whether CTCs also use this route to transmigrate. Like leukocytes, the predominant route of transmigration appears to be the paracellular route, and in vivo evidence of CTCs transmigrating through EC bodies was lacking for a long time. Recently, however, it was shown that breast cancer cells are able to transmigrate through brain capillaries via the transcellular route in vivo $(45,60)$. This 'decision' for the transcellular route may be caused by the idea that the EC junctions in the blood-brain barrier are too tight to effectively cross via the paracellular route (46, 61). For transcellular transmigration, breast cancer cells formed filopodia-like structures that extended into the endothelium, followed by the incorporation of the CTC into the endothelium (45). The molecular mechanisms that regulate this process remain largely unknown; however, MLC phosphorylation appears to play an important role. Breast cancer cells were shown to activate endothelial MLCK upon adhesion to ECs, resulting in local phosphorylation of MLC, which induces endothelial myosin II contraction, followed by transcellular transmigration (44).
To sum up, extravasation or TEM is a very complex process that involves many interactions between the invasive cell and the endothelium. These interactions induce intracellular signalling in ECs that potentially disrupt the barrier, allowing invasive cells to transmigrate. The remainder of this review will zoom in on the central regulators of cancer cell (trans) migration: Rho GTPases.

\section{Rho GTPase signalling in extravasation: a cancer cell point of view}

\section{Rho GTPase signalling networks}

Rho GTPases are small ( 21 kDa) signalling G-proteins and are a part of the Ras superfamily of small GTPases. Like Ras GTPases, Rho GTPases have the property to bind GDP and GTP. By cycling between their inactive, GDP-bound state and their active, GTP-bound state, Rho GTPases can act as 'molecular switches' (62). When localized at cellular membranes, Rho GTPases can get activated by extracellular stimuli and subsequently function as signal transducers (63). By doing so, Rho GTPases regulate many downstream pathways involved in various cellular functions, including motility, polarity, shape and adhesion of cells (63). 'Typical' Rho GTPases include the classical Rho GTPases, RhoA, Rac1 and Cdc42, and RhoB, RhoC, RhoD, RhoF, RhoG, RhoJ, RhoQ, Rac2 and Rac3. The activity of 'typical' Rho GTPases is regulated by guanine nucleotide exchange factors (GEFs), GTPase-activating proteins (GAPs) and guanine nucleotide dissociation inhibitors (GDIs) (Fig. 3). GEFs catalyse the exchange of GDP for GTP, thereby activating the Rho GTPase. RhoGEFs can either be a part of the Dblfamily or the DOCK-family. The Dbl-family comprises a total of 70 RhoGEFs, and the DOCK-family comprises a total of 11 (64). GAPs hydrolyse GTP to GDP, thereby

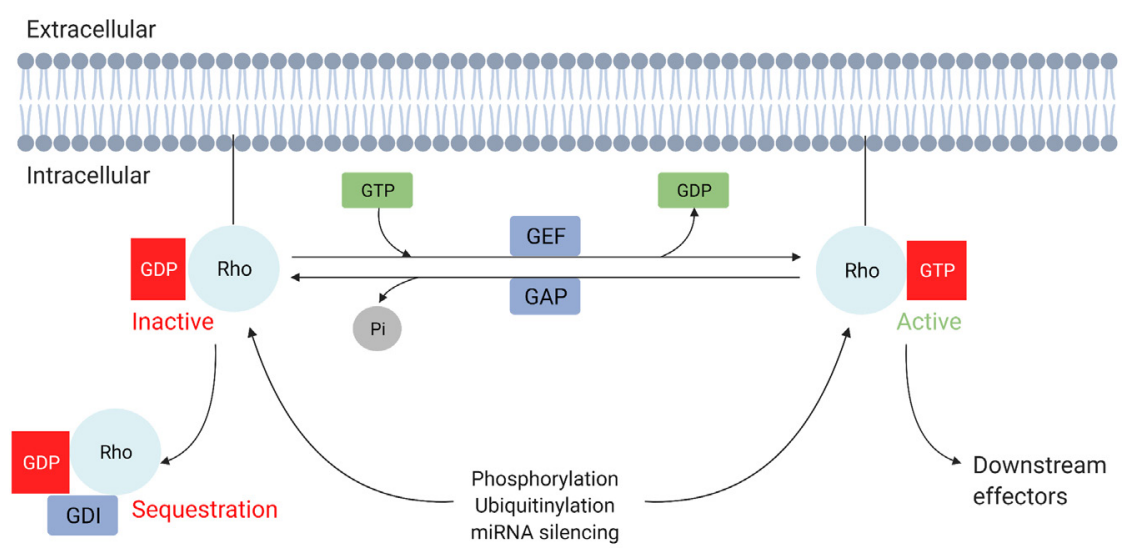

Figure 3

The regulation of typical Rho GTPases. Rho GTPases are active at cellular membranes where they function as signal transducers. A guanine nucleotide exchange factor (GEF) exchanges GDP for GTP, thereby bringing Rho in its GTP-bound, active state. A GTPase-activating protein (GAP) hydrolyses Rho GTP, thereby cleaving off a phosphate group and bringing Rho in its GDP-bound, inactive state. A guanine nucleotide dissociation inhibitor (GDI) extracts RhoGDP from the membrane into the cytosol (sequestration), thereby preventing Rho GTPases to be active at cellular membranes. Post-transcriptional and post-translational modifications of Rho GTPases include phosphorylation, ubiquitinylation and miRNA silencing. https://vb.bioscientifica.com

https://doi.org/10.1530/VB-21-0008 (c) 2021 The authors Published by Bioscientifica Ltd

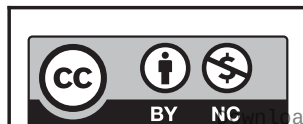

This work is licensed under a Creative Commons Attribution-NonCommercial 4.0 International License. ded from Bioscientifica.com at 04/26/2023 01:51:28PM 
inactivating the Rho GTPase. Although Rho GTPases have intrinsic GTPase activity to initiate the hydrolysis of GTP to GDP, the rate of this reaction is slow, therefore the activity of GAPs is essential (62). To date, approximately 80 RhoGAPs are known, but only a small part has been studied in detail (63). GDIs solubilize Rho GTPases in the cytosol, thus preventing the localization of Rho GTPases at cellular membranes (16). To date, three RhoGDIs are known: RhoGDI 1-3(63). Taken together, the activity of Rho GTPases is thus not only regulated by GDP-GTP cycling but also by membrane association-dissociation cycling.

In the GTP-bound conformation, Rho GTPases can activate many (>100) effector proteins. Most of these effector proteins are kinases, of which the p21-activated kinases (PAKs) and Rho-associated protein kinases (ROCKs or ROKs) are especially involved in cancer cell migration and extravasation $(63,65,66)$. These kinases contain domains that allow binding of Rho GTP, followed by activation of the kinase. For example, PAKs contain a Cdc42-and Rac-interactive binding (CRIB) domain, and ROCKs contain a coiled-coil domain to which Rho can bind $(67,68)$. Upon their activation by Rho GTPases, these kinases phosphorylate downstream molecules involved in various cellular processes. One of the major Rho GTPasemediated downstream processes is the regulation of the actin cytoskeleton and (trans) migration of cancer cells, will be discussed in the next part.

\section{Rho GTPase-mediated regulation of the} actin cytoskeleton

\section{Membrane protrusions}

During cancer cell extravasation, cancer cells continuously alter their actin cytoskeleton to form membrane protrusions, which are important for (trans) migration and adhesion to the endothelium. Many types of such protrusions exist, including invadopodia, lamellipodia, filopodia and podosomes. Invadopodia and podosomes are both F-actin-rich protrusions and together categorized as 'invadosomes'. However, invadopodia are characterized by the invasiveness of cancer cells and degradation of extracellular matrix proteins, whereas podosomes generally function in biological processes unrelated to cancer (69). Lamellipodia are similar F-actin-rich sheet-like protrusions present at the leading edges of cells that are important for cell migration (70). Finally, filopodia are thin protrusions that extend at the end of lamellipodia to probe the environment during migration (70). The formation of each of these protrusions requires actin polymerization, which is centrally regulated by Rho GTPase signalling networks.

\section{Actin polymerization and the role of Rho GTPases}

Actin is present in cells either as monomers (G-actin) or multimers (F-actin). The first step in actin polymerization is the nucleation step, which involves the formation of actin multimers out of monomers. This process is stimulated by two types of actin-nucleating proteins: the actin-related protein 2/3 (Arp2/3) complex and the protein family of formins, both functioning via distinct mechanisms (63) (Fig. 4). Arp2/3-mediated nucleation is characterized by the formation of a branched actin network, present at the leading edges of invadopodia, lamellipodia and filopodia (71). In this way, a pushing force is generated that results in the migration of cells. During this process, nucleationpromoting factors (NPFs) are required to enhance the activity of the Arp2/3 complex. These include WiskottAldrich syndrome protein (WASP), neuronal WASP (N-WASP) and the WASP and Verprolin homologous protein (WAVE) family. All NPFs share a characteristic WCA domain. This domain can bind a G-actin (monomer) with its 'WH2 motif' and can bind to the Arp2/3 complex with its 'CA' part (71). In this way, an NPF 'delivers' G-actin (monomer) towards the Arp2/3 complex (71). Next, the Arp $2 / 3$ complex binds to sides of pre-existing actin filaments, where it serves as a template that can be polymerized, thus forming a branch (72). Certain Rho GTPases can activate NPFs and thereby stimulate Arp2/3mediated cell migration (63) (Fig. 4). More specifically, it has been shown that Cdc42 in its GTP-bound conformation activates WASP (73) and N-WASP (74). Additionally, Rac1 can bind to and activate N-WASP (75) and can also activate WAVEs via an intermediate, IRSp53 $(76,77)$. In this way, the Arp2/3 complex, stimulated by Rho GTPases, is essential for cancer cell migration and invasion (78).

Whereas the Arp2/3 complex stimulates the formation of a branched actin network, formins form large, linear actin filaments via elongation of pre-existing filaments (Fig. 4). Formins stimulate this process in various ways. First, all formins share a formin homology 2 (FH2) domain. This domain stabilizes actin dimers and trimers and thereby enhances the nucleation step (72). In addition, formins bind to filament ends with their FH2 domain, which allows subsequent elongation of the actin filament (79). Lastly, formins inhibit the binding of capping proteins. Capping is the process by which capping proteins bind to filament ends to block elongation. However, the binding of these capping proteins is inhibited when formins are associated to filament ends (72). Like NPFs, Rho GTPases are also involved in formin activation. Not all formins appear to interact with Rho GTPases; however, some members of the predominant diaphanous-related formins (DRF) family

This work is licensed under a Creative Commons Attribution-NonCommercial 4.0 International License. 


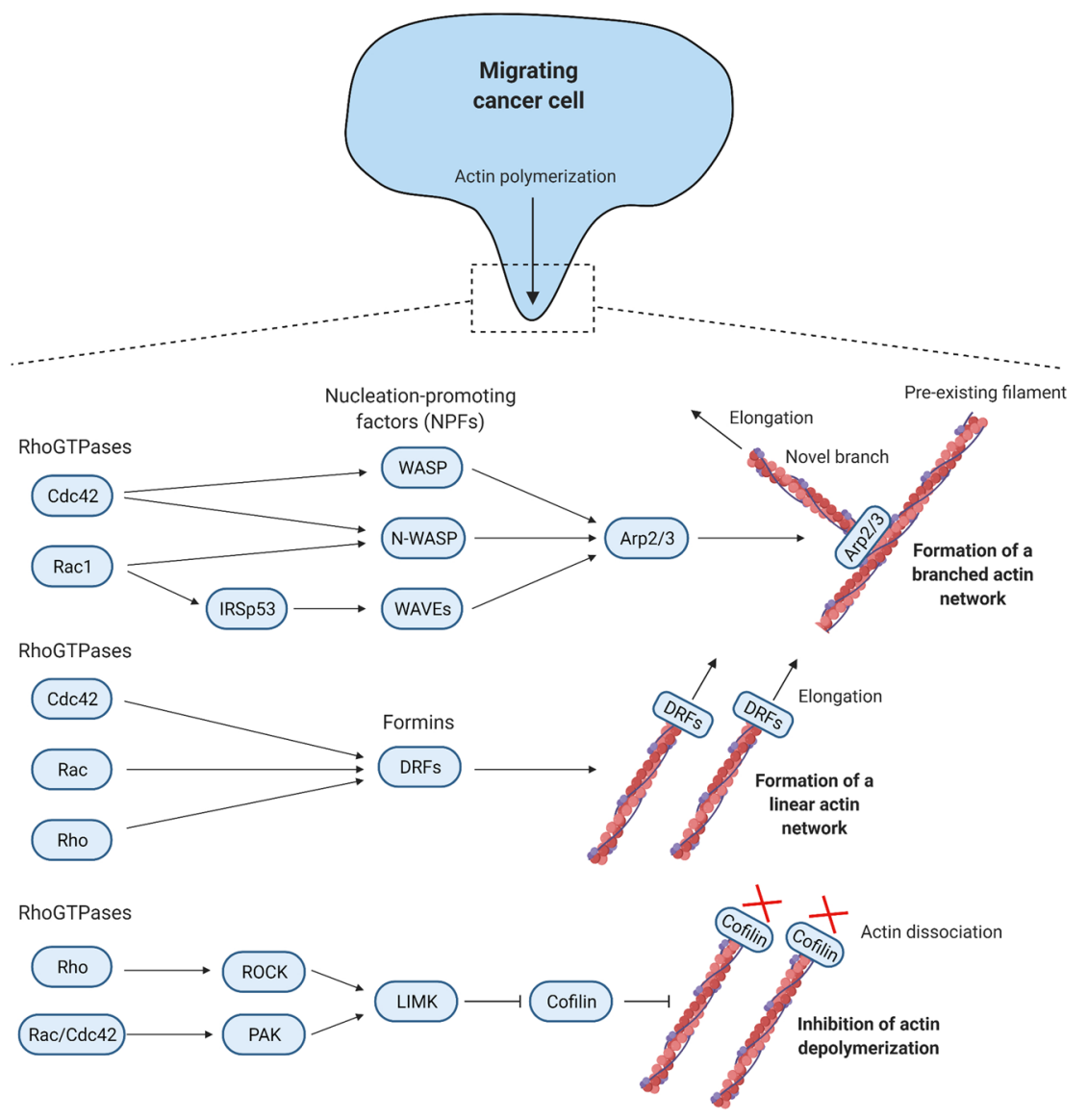

\section{Figure 4}

The role of Rho GTPases in actin polymerization and cancer cell (transendothelial) migration. Actin polymerization in cellular protrusions mediates migration and extravasation of cancer cells. Cdc42 and Rac1 activate nucleation-promoting factors (NPF) and thus stimulate the formation of a branched actin network via Arp2/3. Cdc42, Rac and Rho activate certain members of the diaphanous-related formin (DRF) family and thus stimulate the formation of a linear actin network. Both Rho-ROCK and Rac/Cdc42-PAK inhibit the activity of cofilin via LIMK, thereby inhibiting actin depolymerization. contain a GTPase-binding domain $(72,80)$. Binding of the Rho GTPases Rho, Rac and/or Cdc42 to this domain, relieves the autoinhibition of these DRFs, thus resulting in activation (81) (Fig. 4).

On the contrary of actin polymerization, ADF/cofilin proteins are involved in actin depolymerization. ADF/ cofilin proteins form a family of actin-binding proteins that are known to increase actin dissociation at filament ends and to inhibit filament elongation (82). Cofilin has also been shown to dissociate pre-existing branches formed by the Arp2/3 complex (83). Cofilin can get phosphorylated at Ser3 by LIM-domain-containing kinases (LIMKs) and testis-specific kinases (TESKs), causing it to be inactivated $(82,84)$. The Rho effector ROCK (or ROK) and the Rac/Cdc42 effector PAK both activate LIMKs (63, 82, $85)$. TESKs, on the other hand, are not activated by these Rho GTPases (86). Still, Rho GTPases inhibit ADF/cofilin proteins and actin depolymerization via the Rho-ROCKLIMK and Rac/Cdc42-PAK-LIMK pathways (Fig. 4).

In short, Rho GTPases (Rho, Rac, Cdc42) stimulate actin polymerization by activating NPFs and formins of the DRF family. Additionally, Rho, Rac and Cdc42 inhibit cofilin-mediated actin depolymerization via their effectors
ROCK and PAK. Via these mechanisms, Rho GTPases stimulate the formation of membrane protrusions. Of these protrusions, invadopodia, lamellipodia and filopodia are especially involved in the migration and extravasation of cancer cells, as will be discussed in the next part.

\section{Rho GTPase-mediated formation of invadopodia}

During extravasation, invadopodia are formed for transmigration through the endothelium and subsequent degradation of the underlying extracellular matrix (ECM) (87). Furthermore, the formation of invadopodia has been shown to be essential for the successful extravasation of cancer cells $(10,88)$. As such, the inhibition of invadopodia formation results in an abrogation of cancer cell extravasation (10). Thus, invadopodia formation may be a promising therapeutic target to inhibit extravasation and metastasis.

Invadopodia are characterized by a branched actin network, which is formed by the Cdc42-N-WASPArp2/3 pathway ('Actin polymerization and the role of Rho GTPases' section). Activation of this pathway in invadopodia is initiated upstream by Src-mediated tyrosine phosphorylation and thereby activation of an adaptor

\section{This work is licensed under a Creative Commons Attribution-NonCommercial 4.0 International} License. 
protein, Tks5 $(89,90)$. Tks5, on its turn, together with Nck adaptor proteins, recruits and interacts with several key molecules required for invadopodia assembly, such as N-WASP $(87,89)$. Recently, it was shown that Tks5 also interacts with active Cdc42 (91), and an activating Cdc42GEF, FGD1 (92), thus providing a link between Src, Tks5 and Cdc42-mediated actin polymerization in invadopodia. Additionally, when the activity of Src reaches a certain threshold, it recruits and forms a complex with PI3K and a RhoGEF, ARHGEF5 (93). The formation of this complex generates a positive-feedback mechanism, which enhances Src activation and results in the activation of ARHGEF5. Next, ARHGEF5 activates RhoA and Cdc42 (93, 94). Via these mechanisms, the Rho GTPases RhoA and Cdc42 become activated in invadopodia, which can subsequently stimulate invadopodia maturation by regulating actin polymerization. Cdc42 mediates this process via the Cdc42-N-WASP-Arp2/3 pathway, thus forming a branched actin network (Fig. 4). N-WASP was shown to be only present at the base of invadopodia (95), which suggests that Cdc42-mediated actin polymerization is restricted to that area (94). Subsequent elongation of actin filaments at the base of invadopodia is regulated by formins of the DRF family, which can be activated by Cdc 42 , Rac and Rho $(93,94,96)$ (Fig. 4). This generates a pushing force that is not only required for cancer cell invasion but also extends invadopodia through the endothelium of blood vessels or capillary walls during extravasation (10).

In addition, RhoC plays a crucial role in invadopodia formation. Interestingly, using a FRET-based biosensor, it was shown that RhoC activity is confined to the surroundings of invadopodia (85). This spatialregulated activity of RhoC is regulated by p190RhoGEF and p190RhoGAP. p190RhoGEF is localized around invadopodia to activate RhoC, whereas p190RhoGAP is localized within invadopodia to inactivate RhoC (85). In this way, RhoC is only active at the surroundings of invadopodia, where it activates the aforementioned RhoROCK-LIMK pathway that results in phosphorylation and thus inhibition of cofilin (Fig. 4). Because of this, cofilin is only active within the centre of invadopodia, which is important for creating free actin filament ends that can subsequently be polymerized (85).

On the other hand, RhoG and a RhoG-GEF, SGEF (or ARHGEF26), appear to regulate the disassembly of invadopodia by modulating tyrosine phosphorylation of paxillin (97). Paxillin is an adhesion molecule that is an important component of invadopodia, and its phosphorylation at tyrosine residues was already shown to induce disassembly of invadopodia (98). Thus, the formation of invadopodia requires downregulation of RhoG activity, possibly by a RhoGAP, but this remains unknown (97). Similarly, the Trio-Rac1-PAK1 signalling pathway is involved in invadopodia disassembly by phosphorylating cortactin on Ser113 $(99,100)$. Cortactin promotes invadopodia formation by stimulating actin polymerization (101); however, phosphorylation of cortactin on Ser113 results in its release from F-actin $(99,102)$. Additionally, PAK1 regulates invadopodia disassembly by regulating cofilin and myosin light chain phosphorylation (102). This PAK1-mediated disassembly of invadopodia has an important implication for cancer cell extravasation. Invadopodia sense for chemotactic stimuli, and extravasate only at chemotactic-rich areas, as such areas may be more likely to permit metastatic colonization. However, in areas that are low in chemotactic stimuli and thus not optimal for metastasis, PAK1 mediates invadopodia disassembly and thereby inhibits extravasation. In this way, invadopodia guide cancer cell extravasation during metastasis via PAK1 (102).

An important characteristic of invadopodia and cancer cell migration is the degradation of extracellular matrix (ECM). This is also important during the extravasation of cancer cells, as the ECM that underlies capillary walls is directly degraded during transmigration (94). Degradation of the ECM by invadopodia is mainly facilitated by membrane-type 1 matrix metalloproteinase (MT1-MMP or MMP-14) $(94,103)$. For this to occur, MT1-MMP must first accumulate at invadopodia, which is mediated by the vesicle-tethering exocyst complex and IQGAP1 (104). The vesicle-tethering exocyst complex and IQGAP1 were shown to be essential for the invasive behaviour of cancer cells, and their interaction is triggered by Rho GTPases Cdc42 and RhoA (104).

Taken together, Rho GTPases are involved in many stages of invadopodia formation, including the early stages (assembly of essential proteins), the later stages (actin polymerization) and even invadopodia disassembly. In this way, Rho GTPases regulate the formation of one of the essential structures for cancer cells to migrate and extravasate through capillary walls. Other important structures involved in cancer cell migration and extravasation are lamellipodia and filopodia.

\section{Rho GTPase-mediated formation of lamellipodia/filopodia}

During extravasation, cancer cells also form lamellipodiaand filopodia-like protrusions, which appear to be important for interaction with the microvasculature (30) and for interactions with ECM directly after

\section{This work is licensed under a Creative Commons Attribution-NonCommercial 4.0 International} License. 
extravasation $(5,105)$. The formation of lamellipodia is dependent on the Rho GTPase Rac1 by stimulating actin polymerization $(5,106,107)$. Like invadopodia, lamellipodia are formed by Arp2/3-mediated actin nucleation resulting in a branched actin network. Rac1 mediates this process through the activation of WAVE via the intermediate IRSp53 $(76,107,108)$ (Fig. 4). Importantly, Rac1, WAVE and IRSp53 localize at the tip of lamellipodia to trigger the formation of membrane protrusions (107). By inhibiting Rac1 using either the small molecule inhibitor NSC23766 or HMG-CoA reductase inhibitors (statins), it was shown that the adhesion of CTCs to ECs was reduced, as well as cancer cell extravasation and subsequent metastasis towards the lungs in vivo (109), indicating that Rac1 indeed is essential during extravasation of cancer cells. Filopodia arise at the leading edge of lamellipodia, and their formation is regulated by the Rho GTPase Cdc42. Cdc42 stimulates actin polymerization at the tip of filopodia via the Cdc42-WASP-Arp2/3 pathway (110) (Fig. 4). Additionally, Cdc42 activates IRSp53, which in turn recruits and activates the WASP-family proteins N-WASP and Mena, which further stimulates actin polymerization in filopodia $(110,111)$. Taken together, the classical Rho GTPases Rac1 and Cdc 42 are central regulators of actin polymerization during lamellipodia and filopodia formation, respectively.

\section{Rho GTPase-mediated regulation of cancer} cell-endothelial cell interactions

Adhesion of cancer cells to the endothelium is an essential step in extravasation, a process in which several Rho GTPases are involved. Using an RNA interference screen for all 20 Rho GTPases, it was shown that depletion of RhoA, RhoC, Rac1, Rac3, Cdc42, Rnd2, RhoH and RhoBTB1 each significantly reduced the adhesion of prostate cancer cells to the endothelium (112). Some of these Rho GTPases, including RhoA, RhoC, Rac1 and Cdc42, promote cancer-endothelial cell interaction via the formation of $\mathrm{F}$-actin-rich protrusions ('Rho GTPase-mediated regulation of the actin cytoskeleton' section). For instance, RhoC-ROCK-mediated formation of invadopodia is essential for cancer cell adhesion to the endothelium $(10,66)$. Rho-ROCK signalling was also shown to be responsible for the adhesion of melanoma cells to the blood-brain barrier, thereby promoting extravasation (113). Apart from this, Rho GTPases stimulate cancer cellendothelial cell interactions by regulating the expression of cell-adhesion molecules on their surfaces. For instance, Cdc42 regulates the transcription of $\beta 1$-integrin via the activation of its transcription factor SRF (112). $\beta 1$-integrin is an important adhesion molecule expressed on cancer cells to adhere to the endothelium ('The multistep process of cancer cell extravasation' section). As such, prostate cancer cells depleted of Cdc42 showed reduced adhesion to ECs, reduced extravasation and reduced metastasis formation in vivo (112). Similarly, Rac1 has been shown to stimulate the activation of $\beta 1$-integrin and thereby mediate the interaction between prostate cancer cells and bone marrow ECs (114). Finally, Rac1 has also been implicated in the regulation of E-selectin expression, an important molecule for primary attachment/rolling of cancer cells to ECs (109) ('The multistep process of cancer cell extravasation' section).

\section{Rho GTPase signalling in extravasation: an endothelial point of view}

For a long time, the endothelium was thought to be a passive barrier for CTCs and leukocytes. However, in the past years, it has become clear that ECs are actively involved in regulating extravasation. In this part, the regulation of the endothelial barrier function will be discussed, including how CTCs alter the barrier to transmigrate and metastasize, with a specific focus on the role of Rho GTPase signalling networks during these processes.

\section{The endothelial barrier}

ECs that line blood vessel walls are connected via tight junctions (TJs) and adherens junctions (AJs), thereby forming a tight barrier that is supported by a basement membrane (115) (Fig. 5). These junctions consist of many transmembrane adhesive proteins. TJs connect ECs via claudins, occludins and junctional adhesion molecules (JAMs). AJs connect ECs mainly via VE-cadherin $(48,115)$. The adhesive proteins in TJs are attached to intracellular components such as zonula-occludens (ZO-1, ZO-2, $\mathrm{ZO}-3$ ) and cingulin, that subsequently bind to the actin cytoskeleton $(48,115)$. In AJs, VE-cadherin is intracellularly attached to linker molecules such as $\beta$-catenin, $\alpha$-catenin, p120 or plakoglobin, thereby forming a complex that is also subsequently attached to the actin cytoskeleton (116) (Fig. 5). In addition, other adhesive proteins connect ECs that are not directly a part of either TJs or AJs, such as PECAM-1 (48).

\section{Cancer-cell induced disruption of the} endothelial barrier

To cross this tight barrier via the paracellular route (in between ECs), junctions should be disrupted. Upon firm

This work is licensed under a Creative Commons Attribution-NonCommercial 4.0 International License. 

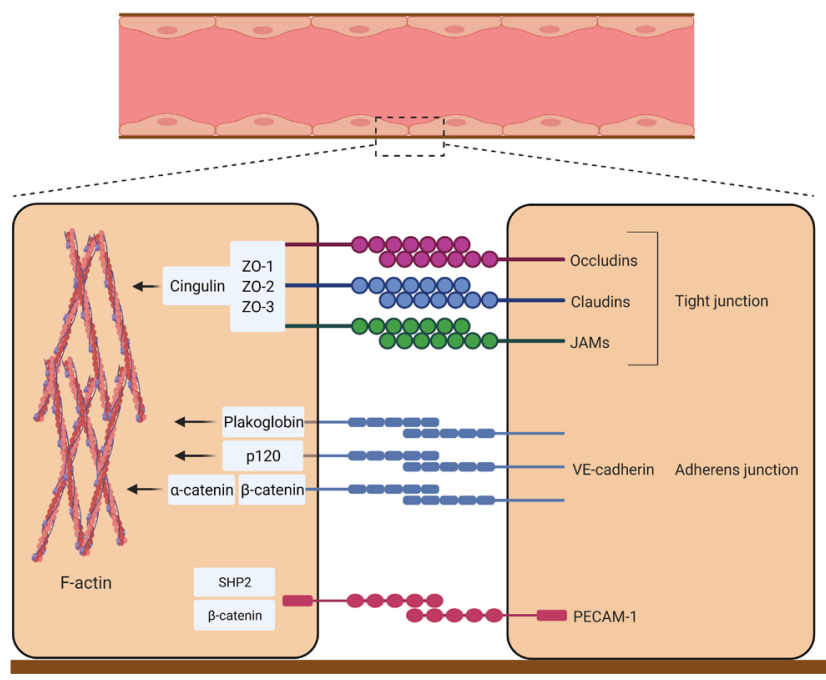

Basement membrane

\section{Figure 5}

The endothelial barrier. Tight junctions (TJS), adherens junctions (AJs) and additional adhesion molecules such as PECAM-1 form the endothelial barrier. TJs mainly consist of occludins, claudins and junctional adhesion molecules (JAMs). AJs mainly consist of VE-cadherin. Adhesion molecules in TJs or AJs are connected to the actin cytoskeleton in ECs via linker proteins, thereby forming a tight barrier that is supported by a basement membrane.

adhesion of cancer cells to ECs, ECs get 'activated'. Selectins and integrins that mediate firm adhesion subsequently induce intracellular signalling cascades in ECs that alter the dynamics of the barrier. These alterations include phosphorylation of VE-cadherin and myosin light chain, actomyosin-mediated tension and stress fibre formation $(5,8)$. Additionally, cancer cells secrete factors that decrease the endothelial barrier function or induce apoptosis or necroptosis in ECs $(5,9)$.

\section{Phosphorylation of VE-cadherin}

VE-cadherin, the major constituent of AJs (Fig. 5), can get phosphorylated by three types of kinases: p21-associated kinases (PAKs), focal adhesion kinases (FAKs) and Src (117). Phosphorylation of VE-cadherin can occur at several tyrosine and serine residues, of which some have been associated with vascular permeability and extravasation, including Ser665, Tyr658, Tyr685 and Tyr731 (48, 49, $50,54)$. Interestingly, these residues are all located in the cytoplasmic domain of VE-cadherin, which includes the juxtamembrane domain (which forms a binding site for p120) and the catenin-binding domain (which forms a binding site for $\beta$-catenin and plakoglobin) $(49,118)$. Phosphorylation of serine and tyrosine residues located in these domains thereby reduces p120-, $\beta$-catenin and plakoglobin-mediated attachment of VE-cadherin to the actin cytoskeleton (Fig. 5) and thus causes disruption of
EC junctions $(49,119)$. This raised the question of whether phosphorylation of VE-cadherin could be a mechanism for cancer cells to locally disrupt the endothelium. Previous studies have already shown that the tyrosine phosphorylation status of the VE-cadherin complex was altered upon adhesion of cancer cells to ECs, but whether the adhesion molecules and molecular mechanisms are involved remained unknown $(55,120)$. Later, it was shown that VE-cadherin tyrosine phosphorylation is induced upon $\alpha 2 \beta 1$ integrin-mediated adhesion of breast, ovarian and prostate cancer cells to ECs, followed by retraction of ECs (121). Similarly, VE-cadherin phosphorylation in ECs is triggered by melanoma cells upon IL-8 secretion or VCAM-1/VLA-4 mediated adhesion that both induce the activation of Src $(8,54)$ (Fig. 6). Additionally, VEGFexpressing cancer cells can induce FAK activation via Src, resulting in FAK-mediated phosphorylation of VE-cadherin at Tyr658 in ECs (122). As such, inhibition of FAK was shown to prevent VEGF-induced Tyr658 phosphorylation of VE-cadherin as well as cancer cell extravasation and formation of lung metastasis in vivo (122).

Phosphorylation of VE-cadherin is, for a part, regulated by Rho GTPase signalling. More specifically, Rac1 and its effector PAK have been shown to be involved in serine phosphorylation of VE-cadherin. As such, activation of Src in ECs by VEGF can induce activation of Rac1 via its regulating GEF, Vav2. Rac1 can subsequently induce serine phosphorylation of VE-cadherin via its effector PAK (48, 123) (Fig. 6). In addition, IL-8 can activate Rac1 via CXCR2 and PI3K $\gamma$, also resulting in serine phosphorylation of VE-cadherin (124) (Fig. 6). However, thus far little remains known about the role of VE-cadherin serine phosphorylation in cancer cell extravasation. Whereas Rac1-PAK is involved in serine phosphorylation, RhoA has been shown to contribute to HRas-induced tyrosine phosphorylation of VE-cadherin (125).

Altogether, cancer cell-induced VE-cadherin phosphorylation is partially mediated by Rho GTPase signalling, which contributes to disruption of EC junctions and is thereby important for extravasation. However, VE-cadherin phosphorylation is by itself not sufficient to decrease the endothelial barrier function (126), additional dynamic alterations of the barrier are required for cancer cells to extravasate.

\section{Phosphorylation of myosin light chain, stress fibre formation}

Myosin II is part of the myosin superfamily of ATPdependent motor proteins that are involved in actinbased motility and contractility of cells. Actin filaments 


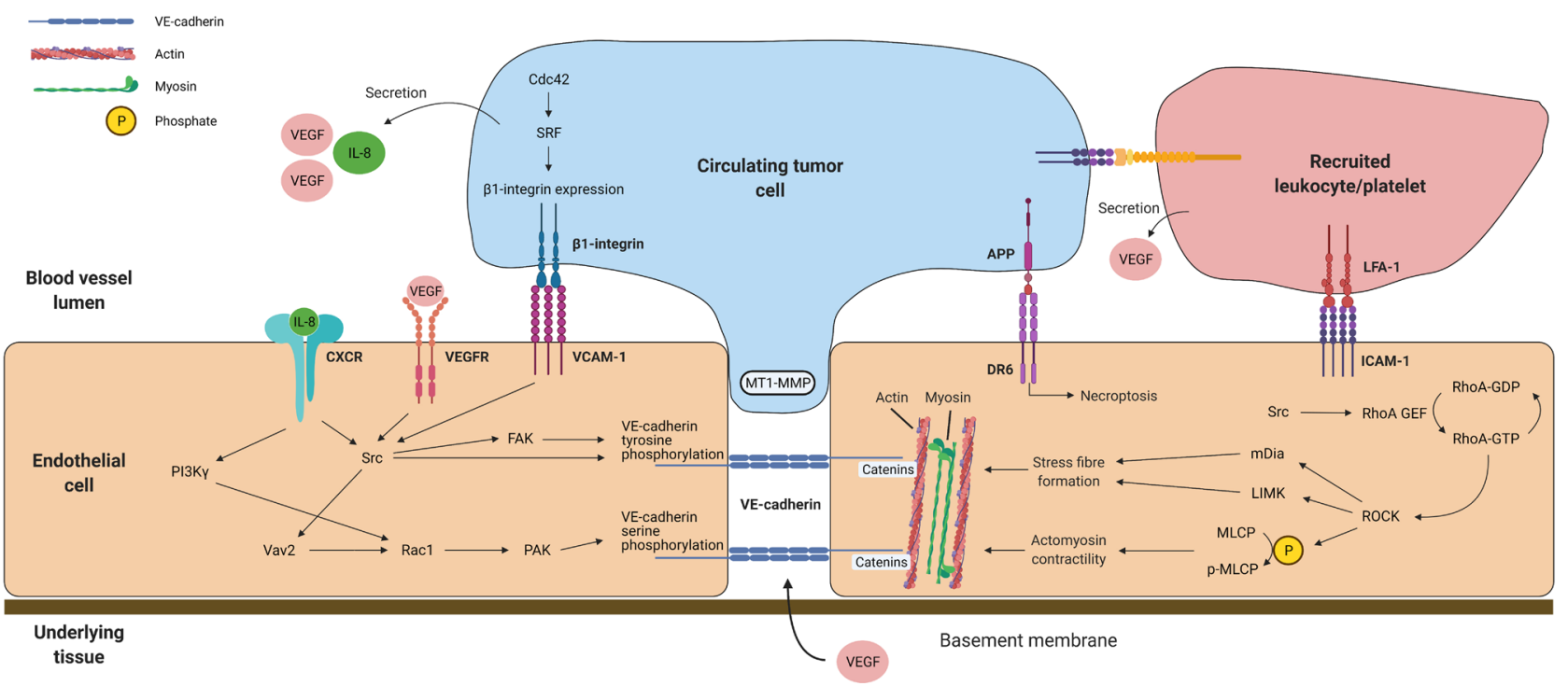

\section{Figure 6}

How cancer cells cross the endothelial barrier and the role of Rho GTPases. Cancer cells induce intracellular signalling in ECs upon adhesion and by secreting various factors, which together contribute to local disruption of the endothelial barrier. Additionally, cancer cells recruit circulating leukocytes and/or platelets, which also contribute to extravasation of cancer cells. Tyrosine and serine phosphorylation of VE-cadherin (left) by Src, FAK and/or PAK can be induced via the secretion of IL-8 and VEGF, combined with integrin-mediated adhesion of cancer cells. Stress fibre formation and actomyosin contractility are centrally regulated by Src and RhoA-ROCK signalling (right). Finally, necroptosis can be induced in ECs upon APP-DR6 interactions (right).

and myosin II can bundle together in stress fibres, a process centrally regulated by RhoA and its effector, ROCK $(21,127)$. To generate stress fibres, ROCK activates mDia, a formin that mediates actin polymerization, and LIMK, a kinase that inhibits actin depolymerization via phosphorylation of cofilin ('Rho GTPase-mediated regulation of the actin cytoskeleton' section; Fig. 6) (127, 128). The formation of stress fibres upon RhoA-ROCK activation induces actomyosin contraction in ECs, which disrupts the barrier function (129). Additionally, myosin II contains myosin light chains (MLCs); phosphorylation of MLCs is induced by myosin light chain kinase (MLCK) and dephosphorylation by myosin light chain phosphatase (MLCP) (129). Phosphorylation of MLC on Thr18 and Ser19 residues increases the interaction of myosin with actin, leading to actomyosin contractility, potential retraction of ECs and the formation of a gap $(21,129)$.

Rho GTPases play a central role in the regulation of MLC phosphorylation, and thus, stress fibre formation. The Rac1 and Cdc42 effectors PAK1 and PAK2 can phosphorylate MLCK, thereby inhibiting its activity and decreasing actomyosin contractility (65). On the other hand, RhoA-ROCK signalling mediates phosphorylation of MLCP, thereby inhibiting its activity and increasing actomyosin contractility (130) (Fig. 6). This suggests that RhoA-ROCK signalling may be a mechanism for cancer cells to induce actomyosin contractility in ECs during extravasation, which was already shown to be the case for leukocytes $(21,131)$. Indeed, the adhesion of small cell lung cancer cells to human brain microvascular endothelial cells induces intracellular RhoA-ROCK activation in ECs, followed by increased MLC phosphorylation and increased extravasation (56). Similarly, stress fibre formation in vertebral microvascular endothelial cells (VMECs) is induced by CX3CL1-mediated activation of Src (132). Src subsequently leads to RhoA-ROCK signalling via activation of p115-RhoGEF, a GEF of RhoA. Activation of this pathway leads to barrier disruption via stress fibre formation and increased extravasation of the lung and renal cancer cells through VMECs (132) (Fig. 6).

Thus, phosphorylation of MLC is important for increasing actomyosin contractility and stress fibre formation in ECs. Upon adhesion to the endothelium, cancer cells can induce RhoA-ROCK signalling in ECs, thereby increasing phosphorylation of MLC and disrupting the endothelial barrier.

\section{Secretion of factors}

In addition to direct cancer cell-endothelial cell interactions via selectins and integrins, cancer cells can also alter intracellular signalling in ECs by secreting various factors (5). For instance, cancer cells secrete TGF- $\beta$, a factor that has especially been associated with increased breast cancer cell invasiveness and metastasis $(7,133)$. 
TGF- $\beta$ has also been shown to promote adhesion to ECs and extravasation of melanoma cells, potentially caused by a TGF- $\beta$-signalling induced endothelial-mesenchymal transition, a process dependent on Rho/ROCK signalling (134). Melanoma cells also secrete SPARC, which promotes extravasation, vascular permeability and lung metastasis formation in vivo (135). For this, SPARC was shown to interact with endothelial VCAM-1, which triggers activating phosphorylation of Src, p38MAPK and myosin light chain 2 (MLC2) (135). In addition, cancer cells secrete VEGF that induces VE-cadherin phosphorylation by stimulating kinases, such as PAK $(48,123)$ and FAK $(122$, 136) (Fig. 6).

Chemokines are important secreted factors by cancer cells to recruit immune cells which promote extravasation. For instance, CCL2 is secreted by breast cancer cells to recruit CCR2+ inflammatory monocytes. Recruited monocytes were shown to subsequently stimulate cancer cell extravasation via VEGF secretion (137). Colon adenocarcinoma cells also secrete CCL2 which subsequently induces vascular permeability in CCR2+ ECs and metastasis formation in vivo, a process dependent on JAK2-Stat5 and p38MAPK signalling (138). Another secreted factor is $12(\mathrm{~S})$ hydroxyeicosatetraenoic acid which is secreted by breast cancer cells and induces retraction of ECs (139). Finally, breast cancer cells secrete angiopoietin-like protein 4 (ANGPTL4) which interacts with endothelial $\alpha 5 \beta 1$-integrin, VE-cadherin and claudin-5 and induces Rac1-PAK signalling in ECs, which loosens cell-cell contacts and thereby facilitates lung metastazation in vivo (140).

Lastly, cancer cells can induce damage to the endothelium by inducing apoptosis or necroptosis. For instance, cancer cells can express amyloid precursor protein (APP), which binds to death receptor 6 (DR6) on ECs, thereby inducing necroptosis of ECs (9) (Fig. 6). However, since not all ECs express DR6, only 10\% of ECs are estimated to be susceptible for cancer cell-induced necroptosis. Similarly, cancer cells have been shown to produce a wide variety of pro-apoptotic factors that induce apoptosis in ECs (5).

\section{Rho GTPase-mediated formation of endothelial cell protrusions}

Apart from invasive cancer cells and leukocytes, ECs also form membrane protrusions during extravasation. During leukocyte extravasation, it has been shown that inflamed ECs form filopodia or 'finger-like' membrane protrusions (141, 142), 'docking structures' (41) or 'cup-like structures'
(42) that extend into the blood vessel lumen. The formation of EC protrusions is centrally regulated by Rho GTPase signalling networks.

A previous study showed that ECs started forming F-actin rich protrusions upon ICAM-1/LFA-1-mediated adhesion of leukocytes to ECs, which were named 'cup-like structures', based on their structure (42). The formation of such protrusions was independent of Rho/ ROCK signalling, which suggested a major role for the Rho GTPases Rac1 and Cdc42 $(21,42)$. Although debate remains about the function of these protrusions, they are currently thought to initiate transmigration of leukocytes but appear not to be required for mediating adhesion to the endothelium $(21,142)$.

Rac1 and RhoG play a major role in the formation of cup-like structures by mediating remodelling of the actin cytoskeleton. Additionally, Rac1 appears to control ICAM-1 clustering in ring-like structures (143). Rac1 and RhoG get activated downstream of ICAM-1 upon adhesion of leukocytes. More specifically, SGEF (SH3-containing GEF), a RhoG-specific GEF, mediates colocalization of ICAM-1 and RhoG, which is followed by the activation of RhoG (144). Depletion of SGEF and RhoG both reduced the formation of protrusions and extravasation but did not alter the adhesion of leukocytes (144). The latter suggests that these cup-like structures indeed are important for initiating transmigration rather than mediating adhesion. Another GEF, Trio, also interacts with ICAM-1. Interaction of ICAM-1 with Trio results in the recruitment and activation Rac1 and RhoG (143). In this way, ICAM-1, Trio and SGEF signalling result in the activation of Rac1 and RhoG, which subsequently stimulate the formation of cup-like structures.

Another EC protrusion involved in extravasation is filopodia or 'finger-like' membrane protrusions, which are F-actin and ICAM-1 rich structures that are important for the adhesion of leukocytes, but dispensable for transmigration (141). Inflammatory signals such as TNF- $\alpha$ released during the initial stages of leukocyte extravasation result in the activation of endothelial Cdc42. Upon activation, Cdc 42 reorganizes the actin cytoskeleton in ECs via its effector PAK4, resulting in the formation of parallel F-actin bundles $(142,145)$. Apart from Cdc42, the motor function of myosin- $\mathrm{X}$ is required to form these filopodialike structures (141). The dependency on both Cdc42 and myosin- $\mathrm{X}$ indeed indicates that these endothelial protrusions can indeed be classified as filopodia.

These endothelial cell protrusions have thus far mainly been studied in the context of leukocyte extravasation. Much remains unknown about the presence and contribution

This work is licensed under a Creative Commons Attribution-NonCommercial 4.0 International License. 
of such protrusions during cancer cell extravasation. Still, some studies provided evidence of ECs forming protrusions upon adhesion of cancer cells $(44,45,146)$, even described as similar to filopodia or 'finger-like' protrusions and cuplike structures $(44,45)$. As cancer cells can also adhere to ECs via ICAM-1 mediated interactions, and/or recruit ICAM-1 expressing leukocytes ('The multistep process of cancer cell extravasation' section), it is possible that the formation of such protrusions functions via similar mechanisms as described above. However, more research is required about the presence, contribution and function of EC protrusions in the context of cancer cell extravasation.

\section{Conclusion}

Cancer cell extravasation is a complex process that involves many interactions between invasive cancer cells and the endothelium. Thus far, many selectins, integrins, other CAMs and secreted factors have been shown to contribute to the extravasation of cancer cells, yet the precise underlying mechanisms by which these molecules act remain incompletely understood. Furthermore, the mechanisms and molecular players that drive the extravasation of cancer cells differ per type of cancer and per type of endothelium, which add further complexity. In recent years, advances have been made, as a novel in vitro and in vivo systems have been developed to visualize and study extravasation (147). For instance, improvements in in vivo imaging techniques have allowed to track individual metastasizing cancer cells in real time, which has led to an increased understanding about the initial steps of extravasation $(4,10,30)$. One of the major challenges of in vitro studies remains to closely resemble the in vivo vasculature that includes CTCs as well as immune cells and platelets, considering these cell types are known to contribute to the extravasation of cancer cells. Ultimately, such studies may result in the identification of novel inhibitors that reduce cancer-endothelial cell adhesion or extravasation of cancer cells, and hence, metastasis.

Rho GTPases are crucial regulators of cancer cell extravasation, and their role in metastasis has been recognized for years. However, whereas the classical Rho GTPases (RhoA, Rac, Cdc42) have been well studied in the context of cancer cell extravasation, little is known about the roles of the other family members during this process. Future challenges remain to better understand the regulation and spatiotemporal control of Rho GTPases by GEFs, GAPs and GDIs. The identification of RhoGEFs and Rho GTPase effectors specifically involved in cancer cell extravasation may lead to the identification of novel inhibitors that reduce extravasation and metastasis in the future.

\section{Declaration of interest}

The authors declare that there is no conflict of interest that could be perceived as prejudicing the impartiality of this review.

\section{Funding}

J D v B is supported by ZonMW NWO Vici grant \# 91819632.

\section{Author contribution statement}

W R wrote the manuscript and produced the figures. J D $\vee \mathrm{B}$ reviewed, edited and supervised the project.

\section{References}

1 Dillekås H, Rogers MS \& Straume O. Are 90\% of deaths from cancer caused by metastases? Cancer Medicine 20198 5574-5576. (https://doi. org/10.1002/cam4.2474)

2 Steeg PS. Targeting metastasis. Nature Reviews: Cancer 201616 201-218. (https://doi.org/10.1038/nrc.2016.25)

3 Kalluri R \& Weinberg RA. The basics of epithelial-mesenchymal transition. Journal of Clinical Investigation 2009119 1420-1428. (https://doi.org/10.1172/JCI39104)

4 Stoletov K, Kato H, Zardouzian E, Kelber J, Yang J, Shattil S \& Klemke R. Visualizing extravasation dynamics of metastatic tumor cells. Journal of Cell Science 2010123 2332-2341. (https://doi.org/10.1242/ jcs.069443)

5 Reymond N, D’Água BB \& Ridley AJ. Crossing the endothelial barrier during metastasis. Nature Reviews: Cancer 201313 858-870. (https:// doi.org/10.1038/nrc3628)

6 Massagué J \& Obenauf AC. Metastatic colonization by circulating tumour cells. Nature 2016529 298-306. (https://doi.org/10.1038/ nature17038)

7 Miles FL, Pruitt FL, Van Golen KL \& Cooper CR. Stepping out of the flow: capillary extravasation in cancer metastasis. Clinical and Experimental Metastasis 200825 305-324. (https://doi.org/10.1007/ s10585-007-9098-2)

8 Weidert E, Pohler SE, Gomez EW \& Dong C. Actinomyosin contraction, phosphorylation of VE-cadherin, and actin remodeling enable melanoma-induced endothelial cell-cell junction disassembly. PLoS ONE 20149 e108092. (https://doi.org/10.1371/journal.pone.0108092)

9 Strilic B, Yang L, Albarrán-Juárez J, Wachsmuth L, Han K, Müller UC, Pasparakis M \& Offermanns S. Tumour-cell-induced endothelial cell necroptosis via death receptor 6 promotes metastasis. Nature 2016536 215-218. (https://doi.org/10.1038/nature19076)

10 Leong HS, Robertson AE, Stoletov K, Leith SJ, Chin CA, Chien AE, Hague MN, Ablack A, Carmine-Simmen K, McPherson VA, et al. Invadopodia are required for cancer cell extravasation and are a therapeutic target for metastasis. Cell Reports 20148 1558-1570. (https://doi.org/10.1016/j.celrep.2014.07.050)

11 Wennerberg K, Rossman KL \& Der CJ. The Ras superfamily at a glance. Journal of Cell Science 2005118 843-846. (https://doi.org/10.1242/ jcs.01660)

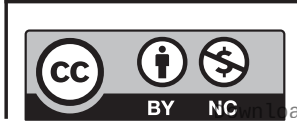

This work is licensed under a Creative Commons Attribution-NonCommercial 4.0 International License. 
12 Humphries B, Wang Z \& Yang C. Rho GTPases: big players in breast cancer initiation, metastasis and therapeutic responses. Cells 20209 2167. (https://doi.org/10.3390/cells9102167)

13 Kagawa Y, Matsumoto S, Kamioka Y, Mimori K, Naito Y, Ishii T, Okuzaki D, Nishida N, Maeda S, Naito A, et al. Cell cycle-dependent Rho GTPase activity dynamically regulates cancer cell motility and invasion in vivo. PLoS ONE 20138 e83629. (https://doi.org/10.1371/ journal.pone.0083629)

14 Barry DM, Xu K, Meadows SM, Zheng Y, Norden PR, Davis GE \& Cleaver O. Cdc42 is required for cytoskeletal support of endothelial cell adhesion during blood vessel formation in mice. Development 2015 142 3058-3070. (https://doi.org/10.1242/dev.125260)

15 Hodge RG \& Ridley AJ. Regulating Rho GTPases and their regulators. Nature Reviews: Molecular Cell Biology 201617 496-510. (https://doi. org/10.1038/nrm.2016.67)

16 Dovas A \& Couchman JR. RhoGDI: multiple functions in the regulation of Rho family GTPase activities. Biochemical Journal 2005 390 1-9. (https://doi.org/10.1042/BJ20050104)

17 Jung H, Yoon SR, Lim J, Cho HJ \& Lee HG. Dysregulation of rho GTPases in human cancers. Cancers 202012 1179. (https://doi. org/10.3390/cancers12051179)

18 Clayton NS \& Ridley AJ. Targeting Rho GTPase signaling networks in cancer. Frontiers in Cell and Developmental Biology 20208 222. (https:// doi.org/10.3389/fcell.2020.00222)

19 Sökeland G \& Schumacher U. The functional role of integrins during intra- and extravasation within the metastatic cascade. Molecular Cancer 201918 12. (https://doi.org/10.1186/s12943-018-0937-3)

20 Butcher EC. Leukocyte-endothelial cell recognition: three (or more) steps to specificity and diversity. Cell 199167 1033-1036. (https://doi. org/10.1016/0092-8674(91)90279-8)

21 Heemskerk N, Van Rijssel J \& Van Buul JD. Rho-GTPase signaling in leukocyte extravasation: an endothelial point of view. Cell Adhesion and Migration 20148 67-75. (https://doi.org/10.4161/cam.28244)

22 Zöllner O, Lenter MC, Blanks JE, Borges E, Steegmaier M, Zerwes HG \& Vestweber D. L-selectin from human, but not from mouse neutrophils binds directly to E-selectin. Journal of Cell Biology 1997136 707-716. (https://doi.org/10.1083/jcb.136.3.707)

23 Azab AK, Quang P, Azab F, Pitsillides C, Thompson B, Chonghaile T, Patton JT, Maiso P, Monrose V, Sacco A, et al. P-selectin glycoprotein ligand regulates the interaction of multiple myeloma cells with the bone marrow microenvironment. Blood 2012119 1468-1478. (https:// doi.org/10.1182/blood-2011-07-368050)

24 Hanley WD, Napier SL, Burdick MM, Schnaar RL, Sackstein R \& Konstantopoulos K. Variant isoforms of CD44 are P- and L-selectin ligands on colon carcinoma cells. FASEB Journal 200620 337-339. (https://doi.org/10.1096/fj.05-4574fje)

25 Aigner S, Ramos CL, Hafezi-Moghadam A, Lawrence MB, Friederichs J, Altevogt P \& Ley K. CD24 mediates rolling of breast carcinoma cells on P-selectin. FASEB Journal 199812 1241-1251. (https://doi.org/10.1096/ fasebj.12.12.1241)

26 Shea DJ, Wirtz D, Stebe KJ \& Konstantopoulos K. Distinct kinetic and mechanical properties govern mucin 16- and podocalyxin-mediated tumor cell adhesion to E- and L-selectin in shear flow. Oncotarget 2015 6 24842-24855. (https://doi.org/10.18632/oncotarget.4704)

27 Strell C, Lang K, Niggemann B, Zaenker KS \& Entschladen F. Surface molecules regulating rolling and adhesion to endothelium of neutrophil granulocytes and MDA-MB-468 breast carcinoma cells and their interaction. Cellular and Molecular Life Sciences 200764 3306-3316. (https://doi.org/10.1007/s00018-007-7402-6)

28 Schlesinger M. Role of platelets and platelet receptors in cancer metastasis. Journal of Hematology and Oncology 201811 125. (https:// doi.org/10.1186/s13045-018-0669-2)

29 Giavazzi R, Foppolo M, Dossi R \& Remuzzi A. Rolling and adhesion of human tumor cells on vascular endothelium under physiological flow conditions. Journal of Clinical Investigation 199392 3038-3044. (https://doi.org/10.1172/JCI116928)
30 Kienast Y, Von Baumgarten L, Fuhrmann M, Klinkert WEF, Goldbrunner R, Herms J \& Winkler F. Real-time imaging reveals the single steps of brain metastasis formation. Nature Medicine 201016 116-122. (https://doi.org/10.1038/nm.2072)

31 Tanaka K, Toiyama Y, Okugawa Y, Okigami M, Inoue Y, Uchida K, Araki T, Mohri Y, Mizoguchi A \& Kusunoki M. In vivo optical imaging of cancer metastasis using multiphoton microscopy: a short review. American Journal of Translational Research 20146 179-187.

32 Glinskii OV, Huxley VH, Glinsky GV, Pienta KJ, Raz A \& Glinsky VV. Mechanical entrapment is insufficient and intercellular adhesion is essential for metastatic cell arrest in distant organs. Neoplasia 20057 522-527. (https://doi.org/10.1593/neo.04646)

33 Desgrosellier JS \& Cheresh DA. Integrins in cancer: biological implications and therapeutic opportunities. Nature Reviews: Cancer 201010 9-22. (https://doi.org/10.1038/nrc2748)

34 Slack-Davis JK, Atkins KA, Harrer C, Daniel Hershey ED \& Conaway M. Vascular cell adhesion molecule- 1 is a regulator of ovarian cancer peritoneal metastasis. Cancer Research 200969 1469-1476. (https://doi. org/10.1158/0008-5472.CAN-08-2678)

35 Klemke M, Weschenfelder T, Konstandin MH \& Samstag Y. High affinity interaction of integrin $\alpha 4 \beta 1$ (VLA-4) and vascular cell adhesion molecule 1 (VCAM-1) enhances migration of human melanoma cells across activated endothelial cell layers. Journal of Cellular Physiology 2007212 368-374. (https://doi.org/10.1002/jcp.21029)

36 Soto MS, Serres S, Anthony DC \& Sibson NR. Functional role of endothelial adhesion molecules in the early stages of brain metastasis. Neuro-Oncology 201416 540-551. (https://doi.org/10.1093/neuonc/ not222)

37 Rahn JJ, Chow JW, Horne GJ, Mah BK, Emerman JT, Hoffman P \& Hugh JC. MUC1 mediates transendothelial migration in vitro by ligating endothelial cell ICAM-1. Clinical and Experimental Metastasis 200522 475-483. (https://doi.org/10.1007/s10585-005-3098-x)

38 Benedicto A, Romayor I \& Arteta B. Role of liver ICAM-1 in metastasis. Oncology Letters 201714 3883-3892. (https://doi.org/10.3892/ ol.2017.6700)

39 Ghislin S, Obino D, Middendorp S, Boggetto N, Alcaide-Loridan C \& Deshayes F. LFA-1 and ICAM-1 expression induced during melanomaendothelial cell co-culture favors the transendothelial migration of melanoma cell lines in vitro. BMC Cancer 201212 455. (https://doi. org/10.1186/1471-2407-12-455)

40 Shaw SK, Ma S, Kim MB, Rao RM, Hartman CU, Froio RM, Yang L, Jones T, Liu Y, Nusrat A, et al. Coordinated redistribution of leukocyte LFA-1 and endothelial cell ICAM-1 accompany neutrophil transmigration. Journal of Experimental Medicine 2004200 1571-1580. (https://doi.org/10.1084/jem.20040965)

41 Barreiro O, Yanez-Mo M, Serrador JM, Montoya MC, VicenteManzanares M, Tejedor R, Furthmayr H \& Sanchez-Madrid F. Dynamic interaction of VCAM-1 and ICAM-1 with moesin and ezrin in a novel endothelial docking structure for adherent leukocytes. Journal of Cell Biology 2002157 1233-1245.

42 Carman CV, Jun CD, Salas A \& Springer TA. Endothelial cells proactively form microvilli-like membrane projections upon intercellular adhesion molecule 1 engagement of leukocyte LFA-1. Journal of Immunology 2003171 6135-6144. (https://doi.org/10.4049/ jimmunol.171.11.6135)

43 Petri B, Kaur J, Long EM, Li H, Parsons SA, Butz S, Phillipson M, Vestweber D, Patel KD, Robbins SM, et al. Endothelial LSP1 is involved in endothelial dome formation, minimizing vascular permeability changes during neutrophil transmigration in vivo. Blood 2011117 942-952. (https://doi.org/10.1182/blood-2010-02270561)

44 Khuon S, Liang L, Dettman RW, Sporn PHS, Wysolmerski RB $\&$ Chew TL. Myosin light chain kinase mediates transcellular intravasation of breast cancer cells through the underlying endothelial cells: a three-dimensional FRET study. Journal of Cell Science 2010123 431-440. (https://doi.org/10.1242/jcs.053793) 
45 Herman H, Fazakas C, Haskó J, Molnár K, Mészáros Á, Nyúl-Tóth Á, Szabó G, Erdélyi F, Ardelean A, Hermenean A, et al. Paracellular and transcellular migration of metastatic cells through the cerebral endothelium. Journal of Cellular and Molecular Medicine 201923 2619-2631. (https://doi.org/10.1111/jcmm.14156)

46 Martinelli R, Zeiger AS, Whitfield M, Sciuto TE, Dvorak A, van Vliet KJ, Greenwood J \& Carman CV. Probing the biomechanical contribution of the endothelium to lymphocyte migration: diapedesis by the path of least resistance. Journal of Cell Science 2014127 3720-3734. (https:// doi.org/10.1242/jcs.148619)

47 Rademakers T, Goedhart M, Hoogenboezem M, García-Ponce A, van Rijssel J, Samus M, Schnoor M, Butz S, Huveneers S, Vestweber D, et al. Hematopoietic stem and progenitor cells use podosomes to transcellularly cross the bone marrow endothelium. Haematologica 2020105 2746-2756. (https://doi.org/10.3324/haematol.2018.196329)

48 Cerutti C \& Ridley AJ. Endothelial cell-cell adhesion and signaling. Experimental Cell Research 2017358 31-38. (https://doi.org/10.1016/j. yexcr.2017.06.003)

49 Allingham MJ, van Buul JD \& Burridge K. ICAM-1-mediated, Src- and Pyk2-dependent vascular endothelial cadherin tyrosine phosphorylation is required for leukocyte transendothelial migration Journal of Immunology 2007179 4053-4064. (https://doi.org/10.4049/ jimmunol.179.6.4053

50 Wessel F, Winderlich M, Holm M, Frye M, Rivera-Galdos R, Vockel M, Linnepe R, Ipe U, Stadtmann A, Zarbock A, et al. Leukocyte extravasation and vascular permeability are each controlled in vivo by different tyrosine residues of VE-cadherin. Nature Immunology 201415 223-230. (https://doi.org/10.1038/ni.2824)

51 Haidari M, Zhang W, Chen Z, Ganjehei L, Warier N, Vanderslice P \& Dixon R. Myosin light chain phosphorylation facilitates monocyte transendothelial migration by dissociating endothelial adherens junctions. Cardiovascular Research 201192 456-465. (https://doi. org/10.1093/cvr/cvr240)

52 Rigor RR, Shen Q, Pivetti CD, Wu MH \& Yuan SY. Myosin light chain kinase signaling in endothelial barrier dysfunction. Medicinal Research Reviews 201333 911-933. (https://doi.org/10.1002/ med.21270)

53 Sheldon R, Moy A, Lindsley K, Shasby S \& Shasby DM. Role of myosin light-chain phosphorylation in endothelial cell retraction. American Journal of Physiology 1993265 L606-L612. (https://doi.org/10.1152/ ajplung.1993.265.6.L606)

54 Aragon-Sanabria V, Pohler SE, Eswar VJ, Bierowski M, Gomez EW $\&$ Dong C. VE-cadherin disassembly and cell contractility in the endothelium are necessary for barrier disruption induced by tumor cells. Scientific Reports 20177 45835. (https://doi.org/10.1038/ srep45835)

55 Cai J, Jiang WG \& Mansel RE. Phosphorylation and disorganization of vascular-endothelial cadherin in interaction between breast cancer and vascular endothelial cells. International Journal of Molecular Medicine 19994 191-195. (https://doi.org/10.3892/ ijmm.4.2.191)

56 Li B, Zhao WD, Tan ZM, Fang WG, Zhu L \& Chen YH. Involvement of Rho/ROCK signalling in small cell lung cancer migration through human brain microvascular endothelial cells. FEBS Letters $2006 \mathbf{5 8 0}$ 4252-4260. (https://doi.org/10.1016/j.febslet.2006.06.056)

57 Mierke CT. Cancer cells regulate biomechanical properties of human microvascular endothelial cells. Journal of Biological Chemistry 2011 286 40025-40037. (https://doi.org/10.1074/jbc.M111.256172)

58 Carman CV, Sage PT, Sciuto TE, de la Fuente MA, Geha RS, Ochs HDD, Dvorak HF, Dvorak AM \& Springer TA. Transcellular diapedesis is initiated by invasive podosomes. Immunity 200726 784-797. (https:// doi.org/10.1016/j.immuni.2007.04.015)

59 Yang L, Froio RM, Sciuto TE, Dvorak AM, Alon R \& Luscinskas FW. ICAM-1 regulates neutrophil adhesion and transcellular migration of TNF- $\alpha$-activated vascular endothelium under flow. Blood 2005106 584-592. (https://doi.org/10.1182/blood-2004-12-4942)
60 Haskó J, Fazakas C, Molnár K, Mészáros Á, Patai R, Szabó G, Erdélyi F, Nyúl-Tóth Á, Győri F, Kozma M, et al. Response of the neurovascular unit to brain metastatic breast cancer cells. Acta Neuropathologica Communications 20197 133. (https://doi.org/10.1186/s40478-0190788-1)

61 Bauer HC, Krizbai IA, Bauer H \& Traweger A. 'You shall not pass'-tight junctions of the blood brain barrier. Frontiers in Neuroscience 20148 392. (https://doi.org/10.3389/fnins.2014.00392)

62 Smithers CC \& Overduin M. Structural mechanisms and drug discovery prospects of Rho GTPases. Cells 2016526 . (https://doi. org/10.3390/cells5020026)

63 Haga RB \& Ridley AJ. Rho GTPases: regulation and roles in cancer cell biology. Small GTPases 20167 207-221. (https://doi.org/10.1080/21541 248.2016.1232583)

64 Cook DR, Rossman KL \& Der CJ. Rho guanine nucleotide exchange factors: regulators of Rho GTPase activity in development and disease. Oncogene 201433 4021-4035. (https://doi.org/10.1038/onc.2013.362)

65 Dummler B, Ohshiro K, Kumar R \& Field J. Pak protein kinases and their role in cancer. Cancer Metastasis Reviews 200928 51-63. (https:// doi.org/10.1007/s10555-008-9168-1)

66 Reymond N, Im JH, Garg R, Cox S, Soyer M, Riou P, Colomba A, Muschel RJ \& Ridley AJ. RhoC and ROCKs regulate cancer cell interactions with endothelial cells. Molecular Oncology 20159 1043-1055. (https://doi.org/10.1016/j.molonc.2015.01.004)

67 Thompson G, Owen D, Chalk PA \& Lowe PN. Delineation of the Cdc42/Rac-binding domain of p21-activated kinase. Biochemistry 1998 37 7885-7891. (https://doi.org/10.1021/bi980140+)

68 Amano M, Nakayama M \& Kaibuchi K. Rho-kinase/ROCK: a key regulator of the cytoskeleton and cell polarity. Cytoskeleton 201067 545-554. (https://doi.org/10.1002/cm.20472)

69 Yamaguchi H \& Condeelis J. Regulation of the actin cytoskeleton in cancer cell migration and invasion. Biochimica et Biophysica Acta 2007 1773 642-652. (https://doi.org/10.1016/j.bbamcr.2006.07.001)

70 Ridley AJ. Rho GTPases and actin dynamics in membrane protrusions and vesicle trafficking. Trends in Cell Biology 2006 16 522-529. (https:// doi.org/10.1016/j.tcb.2006.08.006)

71 Molinie N \& Gautreau A. The Arp2/3 regulatory system and its deregulation in cancer. Physiological Reviews 201898 215-238. (https:// doi.org/10.1152/physrev.00006.2017)

72 Courtemanche N. Mechanisms of formin-mediated actin assembly and dynamics. Biophysical Reviews 201810 1553-1569. (https://doi. org/10.1007/s12551-018-0468-6)

73 Higgs HN \& Pollard TD. Activation by Cdc42 and PIP2 of WiskottAldrich syndrome protein (WASp) stimulates actin nucleation by Arp2/3 complex. Journal of Cell Biology $20001501311-1320$. (https:// doi.org/10.1083/jcb.150.6.1311)

74 Rohatgi R, Ho HYH \& Kirschner MW. Mechanism of N-WASP activation by CDC42 and phosphatidylinositol 4,5-bisphosphate. Journal of Cell Biology 2000150 1299-1310. (https://doi.org/10.1083/ jcb.150.6.1299)

75 Tomasevic N, Jia Z, Russell A, Fujii T, Hartman JJ, Clancy S, Wang M, Beraud C, Wood KW \& Sakowicz R. Differential regulation of WASP and N-WASP by Cdc42, Rac1, Nck, and PI(4,5)P2. Biochemistry 200746 3494-3502. (https://doi.org/10.1021/bi062152y)

76 Miki H, Yamaguchi H, Suetsugu S \& Takenawa T. IRSp53 is an essential intermediate between Rac and WAVE in the regulation of membrane ruffling. Nature 2000408 732-735. (https://doi.org/10.1038/35047107)

77 Chen B, Chou HT, Brautigam CA, Xing W, Yang S, Henry L, Doolittle LK, Walz T \& Rosen MK. Rac1 GTPase activates the WAVE regulatory complex through two distinct binding sites. eLife 20176 29795. (https://doi.org/10.7554/eLife.29795)

78 Rauhala HE, Teppo S, Niemelä S \& Kallioniemi A. Silencing of the Arp2/3 complex disturbs pancreatic cancer cell migration. Anticancer Research 201333 45-52.

79 Pruyne D, Evangelista M, Yang C, Bi E, Zigmond S, Bretscher A \& Boone C. Role of formins in actin assembly: nucleation and barbed-

This work is licensed under a Creative Commons Attribution-NonCommercial 4.0 International License. dicen from Bioscientifica com at 04/26/2023 01:51:28PM 
end association. Science 2002297 612-615. (https://doi.org/10.1126/ science.1072309)

80 Goode BL \& Eck MJ. Mechanism and function of formins in the control of actin assembly. Annual Review of Biochemistry 200776 593-627. (https://doi.org/10.1146/annurev. biochem.75.103004.142647)

81 Kühn S \& Geyer M. Formins as effector proteins of rho GTPases. Small GTPases 20145 e29513. (https://doi.org/10.4161/sgtp.29513)

82 Sit ST \& Manser E. Rho GTPases and their role in organizing the actin cytoskeleton. Journal of Cell Science 2011 124 679-683. (https://doi. org/10.1242/jcs.064964)

83 Chan C, Beltzner CC \& Pollard TD. Cofilin dissociates Arp2/3 complex and branches from actin filaments. Current Biology 200919 537-545 (https://doi.org/10.1016/j.cub.2009.02.060)

84 Wang L, Buckley AF \& Spurney RF. Regulation of cofilin phosphorylation in glomerular podocytes by testis specific kinase 1 (TESK1). Scientific Reports 20188 12286. (https://doi.org/10.1038/ s41598-018-30115-3)

85 Bravo-Cordero JJ, Oser M, Chen X, Eddy R, Hodgson L \& Condeelis J. A novel spatiotemporal RhoC activation pathway locally regulates cofilin activity at invadopodia. Current Biology 201121 635-644 (https://doi.org/10.1016/j.cub.2011.03.039)

86 Toshima J, Toshima JY, Amano T, Yang N, Narumiya S \& Mizuno K. Cofilin phosphorylation by protein kinase testicular protein kinase 1 and its role in integrin-mediated actin reorganization and focal adhesion formation. Molecular Biology of the Cell 200112 1131-1145. (https://doi.org/10.1091/mbc.12.4.1131)

87 Eddy RJ, Weidmann MD, Sharma VP \& Condeelis JS. Tumor cell invadopodia: invasive protrusions that orchestrate metastasis. Trends in Cell Biology 201727 595-607. (https://doi.org/10.1016/j. tcb.2017.03.003)

88 Tokui N, Yoneyama MS, Hatakeyama S, Yamamoto H, Koie T, Saitoh H, Yamaya K, Funyu T, Nakamura T, Ohyama C, et al. Extravasation during bladder cancer metastasis requires cortactin-mediated invadopodia formation. Molecular Medicine Reports 20149 1142-1146. (https://doi.org/10.3892/mmr.2014.1965)

89 Stylli SS, Stacey TTI, Verhagen AM, Xu SS, Pass I, Courtneidge SA \& Lock P. Nck adaptor proteins link Tks5 to invadopodia actin regulation and ECM degradation. Journal of Cell Science 2009122 2727-2740. (https://doi.org/10.1242/jcs.046680)

90 Iizuka S, Abdullah C, Buschman MD, Diaz B \& Courtneidge SA. The role of Tks adaptor proteins in invadopodia formation, growth and metastasis of melanoma. Oncotarget 20167 78473-78486. (https://doi. org/10.18632/oncotarget.12954)

91 Bagci H, Sriskandarajah N, Robert A, Boulais J, Elkholi IE, Tran V, Lin ZY, Thibault MP, Dubé N, Faubert D, et al. Mapping the proximity interaction network of the Rho-family GTPases reveals signalling pathways and regulatory mechanisms. Nature Cell Biology 202022 120-134. (https://doi.org/10.1038/s41556-019-0438-7)

92 Zagryazhskaya-Masson A, Monteiro P, Macé AS, Castagnino A Ferrari R, Infante E, Duperray-Susini A, Dingli F, Lanyi A, Loew D, et al. Intersection of TKS5 and FGD1/CDC42 signaling cascades directs the formation of invadopodia. Journal of Cell Biology 2020219 e201910132. (https://doi.org/10.1083/jcb.201910132)

93 Kuroiwa M, Oneyama C, Nada S \& Okada M. The guanine nucleotide exchange factor Arhgef5 plays crucial roles in Src-induced podosome formation. Journal of Cell Science $2011 \mathbf{1 2 4}$ 1726-1738. (https://doi. org/10.1242/jcs.080291)

94 Spuul P, Ciufici P, Veillat V, Leclercq A, Daubon T, Kramer IJ \& Génot E. Importance of RhoGTPases in formation, characteristics, and functions of invadosomes. Small GTPases 20145 e28195. (https://doi. org/10.4161/sgtp.28713)

95 Lorenz M, Yamaguchi H, Wang Y, Singer RH \& Condeelis J. Imaging sites of N-WASP activity in lamellipodia and invadopodia of carcinoma cells. Current Biology 200414 697-703. (https://doi.org/10.1016/j. cub.2004.04.008)
96 Lammers M, Meyer S, Kühlmann D \& Wittinghofer A. Specificity of interactions between mDia isoforms and Rho proteins. Journal of Biological Chemistry 2008283 35236-35246. (https://doi.org/10.1074/ jbc.M805634200)

97 Goicoechea SM, Zinn A, Awadia SS, Snyder K, Garcia-Mata R \& Rho A. A RhoG-mediated signaling pathway that modulates invadopodia dynamics in breast cancer cells. Journal of Cell Science 2017130 1064-1077. (https://doi.org/10.1242/jcs.195552)

98 Badowski C, Pawlak G, Grichine A, Chabadel A, Oddou C, Jurdic P, Pfaff M, Albigès-Rizo C \& Block MR. Paxillin phosphorylation controls invadopodia/podosomes spatiotemporal organization. Molecular Biology of the Cell 200819 633-645. (https://doi.org/10.1091/mbc.e0601-0088)

99 Moshfegh Y, Bravo-Cordero JJ, Miskolci V, Condeelis J \& Hodgson L. A Trio-Rac1-Pak1 signalling axis drives invadopodia disassembly. Nature Cell Biology 201416 571-583. (https://doi.org/10.1038/ncb2972)

100 Jeannot P, Nowosad A, Perchey RT, Callot C, Bennana E, Katsube T, Mayeux P, Guillonneau F, Manenti S \& Besson A. P27Kip1 promotes invadopodia turnover and invasion through the regulation of the PAK1/cortactin pathway. eLife 20176 e22207. (https://doi.org/10.7554/ eLife.22207)

101 Weed SA \& Parsons JT. Cortactin: coupling membrane dynamics to cortical actin assembly. Oncogene 200120 6418-6434. (https://doi. org/10.1038/sj.onc.1204783)

102 Williams KC, Cepeda MA, Javed S, Searle K, Parkins KM, Makela AV, Hamilton AM, Soukhtehzari S, Kim Y, Tuck AB, et al. Invadopodia are chemosensing protrusions that guide cancer cell extravasation to promote brain tropism in metastasis. Oncogene 201938 3598-3615. (https://doi.org/10.1038/s41388-018-0667-4)

103 Itoh Y. MT1-MMP: a key regulator of cell migration in tissue. IUBMB Life 200658 589-596. (https://doi.org/10.1080/15216540600962818)

104 Sakurai-Yageta M, Recchi C, Le Dez G, Sibarita JB, Daviet L, Camonis J, D'Souza-Schorey C \& Chavrier P. The interaction of IQGAP1 with the exocyst complex is required for tumor cell invasion downstream of Cdc42 and RhoA. Journal of Cell Biology 2008181 985-998. (https:// doi.org/10.1083/jcb.200709076)

105 Shibue T, Brooks MW, Fatih Inan MF, Reinhardt F \& Weinberg RA. The outgrowth of micrometastases is enabled by the formation of filopodium-like protrusions. Cancer Discovery 20122 706-721. (https:// doi.org/10.1158/2159-8290.CD-11-0239)

106 Ridley AJ, Paterson HF, Johnston CL, Diekmann D \& Hall A. The small GTP-binding protein rac regulates growth factor-induced membrane ruffling. Cell 199270 401-410. (https://doi.org/10.1016/00928674(92)90164-8)

107 Mehidi A, Rossier O, Schaks M, Chazeau A, Binamé F, Remorino A, Coppey M, Karatas Z, Sibarita JB, Rottner K, et al. Transient activations of Rac1 at the lamellipodium tip trigger membrane protrusion. Current Biology 201929 2852-2866.e5. (https://doi.org/10.1016/j. cub.2019.07.035)

108 Marchesin V, Montagnac G \& Chavrier P. ARF6 promotes the formation of Rac1 and WAVE-dependent ventral F-actin rosettes in breast cancer cells in response to epidermal growth factor. PLOS ONE 201510 e0121747. (https://doi.org/10.1371/journal.pone.0121747)

109 Hamalukic M, Huelsenbeck J, Schad A, Wirtz S, Kaina B \& Fritz G. Rac1-regulated endothelial radiation response stimulates extravasation and metastasis that can be blocked by HMG-CoA Reductase Inhibitors. PLoS ONE 20116 e26413. (https://doi. org/10.1371/journal.pone.0026413)

110 Pellegrin S \& Mellor H. The Rho family GTPase Rif induces filopodia through mDia2. Current Biology 200515 129-133. (https://doi. org/10.1016/j.cub.2005.01.011)

111 Lim KB, Bu W, Goh WI, Koh E, Ong SH, Pawson T, Sudhaharan T \& Ahmed S. The Cdc42 effector IRSp53 generates filopodia by coupling membrane protrusion with actin dynamics. Journal of Biological Chemistry 2008283 20454-20472. (https://doi.org/10.1074/jbc. M710185200)

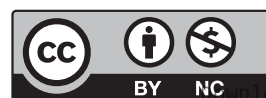

This work is licensed under a Creative Commons Attribution-NonCommercial 4.0 International License. led from Bioscientifica com at 04/26/2023 01:51:28PM 
112 Reymond N, Im JH, Garg R, Vega FM, D'agua BB, Riou P, Cox S, Valderrama F, Muschel RJ \& Ridley AJ. Cdc42 promotes transendothelial migration of cancer cells through $\beta 1$ integrin. Journal of Cell Biology 2012199 653-668. (https://doi.org/10.1083/ jcb.201205169)

113 Wilhelm I, Fazakas C, Molnár J, Haskó J, Végh AG, Cervenak L, Nagyőszi P, Nyúl-Tóth A, Farkas AE, Bauer H, et al. Role of Rho/ROCK signaling in the interaction of melanoma cells with the blood-brain barrier. Pigment Cell and Melanoma Research 201427 113-123. (https:// doi.org/10.1111/pcmr.12169)

114 Chatterjee M, Sequeira L, Jenkins-Kabaila M, Dubyk CW, Pathak S \& van Golen KL. Individual Rac GTPases mediate aspects of prostate cancer cell and bone marrow endothelial cell interactions. Journal of Signal Transduction 20112011 541851. (https://doi org/10.1155/2011/541851)

115 Dejana E, Orsenigo F, Molendini C, Baluk P \& McDonald DM. Organization and signaling of endothelial cell-to-cell junctions in various regions of the blood and lymphatic vascular trees. Cell and Tissue Research 2009335 17-25. (https://doi.org/10.1007/s00441-0080694-5)

116 Bazzoni G \& Dejana E. Endothelial cell-to-cell junctions: molecular organization and role in vascular homeostasis. Physiological Reviews 200484 869-901. (https://doi.org/10.1152/physrev.00035.2003)

117 Gavard J. Endothelial permeability and VE-cadherin: a wacky comradeship. Cell Adhesion and Migration 20137 465-471. (https://doi. org/10.4161/cam.27330)

118 Vincent PA, Xiao K, Buckley KM \& Kowalczyk AP. VE-cadherin: adhesion at arm's length. American Journal of Physiology: Cell Physiology 2004286 C987-C997. (https://doi.org/10.1152/ ajpcell.00522.2003)

119 Potter MD, Barbero S \& Cheresh DA. Tyrosine phosphorylation of VE-cadherin prevents binding of p120- and $\beta$-catenin and maintains the cellular mesenchymal state. Journal of Biological Chemistry 2005 280 31906-31912. (https://doi.org/10.1074/jbc.M505568200)

120 Lewalle JM, Bajou K, Desreux J, Mareel M, Dejana E, Noël A \& Foidart JM. Alteration of interendothelial adherens junctions following tumor cell-endothelial cell interaction in vitro. Experimental Cell Research 1997237 347-356. (https://doi.org/10.1006/ excr.1997.3799)

121 Haidari M, Zhang W, Caivano A, Chen Z, Ganjehei L, Mortazavi A, Stroud C, Woodside DG, Willerson JT \& Dixon RA. Integrin $\alpha 2 \beta 1$ mediates tyrosine phosphorylation of vascular endothelial cadherin induced by invasive breast cancer cells. Journal of Biological Chemistry 2012287 32981-32992. (https://doi.org/10.1074/jbc.M112.395905)

122 Jean C, Chen XL, Nam JO, Tancioni I, Uryu S, Lawson C, Ward KK, Walsh CT, Miller NL, Ghassemian M, et al. Inhibition of endothelial FAK activity prevents tumor metastasis by enhancing barrier function. Journal of Cell Biology 2014204 247-263. (https://doi.org/10.1083/ jcb.201307067)

123 Garrett TA, Van Buul JD \& Burridge K. VEGF-induced Rac1 activation in endothelial cells is regulated by the guanine nucleotide exchange factor Vav2. Experimental Cell Research 2007313 3285-3297. (https:// doi.org/10.1016/j.yexcr.2007.05.027)

124 Gavard J, Hou X, Qu Y, Masedunskas A, Martin D, Weigert R, Li X $\&$ Gutkind JS. A role for a CXCR2/phosphatidylinositol 3-kinase $\gamma$ signaling axis in acute and chronic vascular permeability. Molecular and Cellular Biology 200929 2469-2480. (https://doi.org/10.1128/ MCB.01304-08)

125 Haidari M, Zhang W, Chen Z, Ganjehei L, Mortazavi A, Warier N, Vanderslice P \& Dixon RA. Atorvastatin preserves the integrity of endothelial adherens junctions by inhibiting vascular endothelial cadherin tyrosine phosphorylation. Experimental Cell Research 2012 318 1673-1684. (https://doi.org/10.1016/j.yexcr.2012.05.009)

126 Adam AP, Sharenko AL, Pumiglia K \& Vincent PA. Src-induced tyrosine phosphorylation of VE-cadherin is not sufficient to decrease barrier function of endothelial monolayers. Journal of Biological Chemistry 2010285 7045-7055. (https://doi.org/10.1074/jbc.M109.079277)

127 Narumiya S, Tanji M \& Ishizaki T. Rho signaling, ROCK and mDia1, in transformation, metastasis and invasion. Cancer Metastasis Reviews 200928 65-76. (https://doi.org/10.1007/s10555-008-9170-7)

128 Maekawa M, Ishizaki T, Boku S, Watanabe N, Fujita A, Iwamatsu A, Obinata T, Ohashi K, Mizuno K \& Narumiya S. Signaling from Rho to the actin cytoskeleton through protein kinases ROCK and LIM-kinase. Science 1999285 895-898. (https://doi.org/10.1126/ science.285.5429.895)

129 Shen Q, Rigor RR, Pivetti CD, Wu MH \& Yuan SY. Myosin light chain kinase in microvascular endothelial barrier function. Cardiovascular Research 201087 272-280. (https://doi.org/10.1093/cvr/cvq144)

130 Yao L, Romero MJ, Toque HA, Yang G, Caldwell RB \& Caldwell RW. The role of RhoA/Rho kinase pathway in endothelial dysfunction. Journal of Cardiovascular Disease Research 20101 165-170. (https://doi. org/10.4103/0975-3583.74258)

131 Saito H, Minamiya Y, Kitamura M, Saito S, Enomoto K, Terada K \& Ogawa J. Endothelial myosin light chain kinase regulates neutrophil migration across human umbilical vein endothelial cell monolayer. Journal of Immunology $1998 \mathbf{1 6 1}$ 1533-1540.

132 Yi L, Liang Y, Zhao Q, Wang H \& Dong J. CX3CL1 induces vertebral microvascular barrier dysfunction via the Src/P115-RhoGEF/ROCK signaling pathway. Frontiers in Cellular Neuroscience 20201496. (https://doi.org/10.3389/fncel.2020.00096)

133 Drabsch Y \& Ten Dijke P. TGF- $\beta$ signaling in breast cancer cell invasion and bone metastasis. Journal of Mammary Gland Biology and Neoplasia 2011 16 97-108. (https://doi.org/10.1007/s10911-011-9217-1)

134 Krizbai IA, Gasparics Á, Nagyőszi P, Fazakas C, Molnár J, Wilhelm I, Bencs R, Rosivall L \& Sebe A. Endothelial-mesenchymal transition of brain endothelial cells: possible role during metastatic extravasation. PLoS ONE 201510 e0119655. (https://doi.org/10.1371/journal. pone.0119655)

135 Tichet M, Prodhomme V, Fenouille N, Ambrosetti D, Mallavialle A, Cerezo M, Ohanna M, Audebert S, Rocchi S, Giacchero D, et al. Tumour-derived SPARC drives vascular permeability and extravasation through endothelial VCAM1 signalling to promote metastasis. Nature Communications 20156 6993. (https://doi.org/10.1038/ncomms7993)

136 Chen XL, Nam JO, Jean C, Lawson C, Walsh CT, Goka E, Lim ST, Tomar A, Tancioni I, Uryu S, et al. VEGF-induced vascular permeability is mediated by FAK. Developmental Cell 201222 146-157. (https://doi. org/10.1016/j.devcel.2011.11.002)

137 Qian BZ, Li J, Zhang H, Kitamura T, Zhang J, Campion LR, Kaiser EA, Snyder LA \& Pollard JW. CCL2 recruits inflammatory monocytes to facilitate breast-tumour metastasis. Nature 2011475 222-225. (https:// doi.org/10.1038/nature10138)

138 Wolf MJ, Hoos A, Bauer J, Boettcher S, Knust M, Weber A, Simonavicius N, Schneider C, Lang M, Stürzl M, et al. Endothelial CCR2 signaling induced by colon carcinoma cells enables extravasation via the JAK2-Stat5 and p38MAPK pathway. Cancer Cell 201222 91-105. (https://doi.org/10.1016/j.ccr.2012.05.023)

139 Uchide K, Sakon M, Ariyoshi H, Nakamori S, Tokunaga M \& Monden M. Cancer cells cause vascular endothelial cell (vEC) retraction via 12(S)HETE secretion; the possible role of cancer cell derived microparticle. Annals of Surgical Oncology 2007 14 862-868. (https://doi.org/10.1245/s10434-006-9225-3)

140 Huang RL, Teo Z, Chong HC, Zhu P, Tan MJ, Tan CK, Lam CR, Sng MK, Leong DT, Tan SM, et al. ANGPTL4 modulates vascular junction integrity by integrin signaling and disruption of intercellular VE-cadherin and claudin-5 clusters. Blood 2011 118 3990-4002. (https://doi.org/10.1182/blood-2011-01-328716)

141 Kroon J, Schaefer A, van Rijssel J, Hoogenboezem M, van Alphen F, Hordijk P, Stroes ESG, Strömblad S, van Rheenen J \& van Buul JD. Inflammation-sensitive myosin-X functionally supports leukocyte extravasation by Cdc42-mediated ICAM-1-rich endothelial filopodia

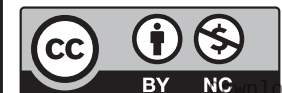

This work is licensed under a Creative Commons Attribution-NonCommercial 4 .0 International License. ded from Bioscientifica, com at 04/26/2023 01:51:28PM 
formation. Journal of Immunology 2018200 1790-1801. (https://doi. org/10.4049/jimmunol.1700702)

142 van Steen ACI, van der Meer WJ, Hoefer IE \& van Buul JD. Actin remodelling of the endothelium during transendothelial migration of leukocytes. Atherosclerosis 2020315 102-110. (https://doi. org/10.1016/j.atherosclerosis.2020.06.004)

143 Van Rijssel J, Kroon J, Hoogenboezem M, Van Alphen FPJ, De Jong RJ, Kostadinova E, Geerts D, Hordijk PL \& van Buul JD. The Rho-guanine nucleotide exchange factor Trio controls leukocyte transendothelial migration by promoting docking structure formation. Molecular Biology of the Cell 201223 2831-2844. (https://doi.org/10.1091/mbc. E11-11-0907)

144 Van Buul JD, Allingham MJ, Samson T, Meller J, Boulter E, GarcíaMata R \& Burridge K. RhoG regulates endothelial apical cup assembly downstream from ICAM1 engagement and is involved in leukocyte trans-endothelial migration. Journal of Cell Biology 2007178 1279-1293. (https://doi.org/10.1083/jcb.200612053)

145 Abo A, Qu J, Cammarano MS, Dan C, Fritsch A, Baud V, Belisle B \& Minden A. PAK4, a novel effector for Cdc42Hs, is implicated in the reorganization of the actin cytoskeleton and in the formation of filopodia. EMBO Journal 199817 6527-6540. (https://doi.org/10.1093/ emboj/17.22.6527)

146 Kanada M, Zhang J, Yan L, Sakurai T \& Terakawa S. Endothelial cellinitiated extravasation of cancer cells visualized in zebrafish. PeerJ 2014 2 e688. (https://doi.org/10.7717/peerj.688)

147 Cheng X \& Cheng K. Visualizing cancer extravasation: from mechanistic studies to drug development. Cancer Metastasis Reviews 202140 71-88. (https://doi.org/10.1007/s10555-020-09942-2)

Received in final form 13 September 2021

Accepted 14 September 2021

Accepted Manuscript published online 14 September 2021 (c) 2021 The authors Published by Bioscientifica Ltd

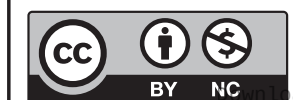

This work is licensed under a Creative Commons Attribution-NonCommercial 4.0 International

License.
ded from Bioscientifica.com at $04 / 26 / 2023$ 01:51:28PM 